NBSIR 73-311

\title{
STUDY OF A \\ MOBILE LIQUID OXYGEN-NITROGEN GENERATOR
}

Peter C. Vander Arend

Stanley T. Stoy

Cryogenic Consultants, Inc.

Allentown. Pennsylvania 18103

Thomas R. Strobridge

Cryogenics Division

Institute for Basic Standards

National Bureau of Standards

Boulder, Colorado 80302

December 15, 1972

Final Report

Prepared for

NAVAL AIR ENGINEERING CENTER

Philadelphia, Pennsylvania 19122 

NBSIR 73-311

\section{STUDY OF A}

MOBILE LIQUID OXYGEN-NITROGEN GENERATOR

Peter C. Vander Arend

Stanley T. Stoy

Cryogenic Consultants, Inc.

Allentown, Pennsylvania 18103

Thomas R. Strobridge

Cryogenics Division

Institute for Basic Standards

National Bureau of Standards

Boulder, Colorado 80302

December 15,1972

Final Report

Prepared for

NAVAL AIR ENGINEERING CENTER

Philadelphia, Pennsylvania 19122

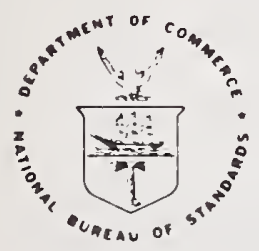

U.S. DEPARTMENT OF COMMERCE, Frederick B. Dent, Secretary NATIONAL BUREAU OF STANDARDS, Richard $W$. Roberts, Director 


\section{Preface}

This study deals with the preliminary design of a mobile liquid oxygen-nitrogen generator. The objective is to increase production over existing units while maintaining the same overall physical dimensions and a similar air compression system. Because of the sponsor's request and because almost all data concerning air separation are given in English units, that system is used in this report. Conversion to the SI System of units is accomplished with the following conversion factors $*$ :

$$
\begin{aligned}
& \text { pound } \times 0.4536=\text { kilogram } \\
& \text { foot } \times 3.0480=\text { meter } \\
& \text { liter } \times 10^{-3}=\mathrm{m}^{3} \\
& \text { PSl } \times 0.6895=\mathrm{N} / \mathrm{cm}^{2} \\
& \text { Btu } / \mathrm{b} \times 2.326=\text { joule } / \text { gram } \\
& \text { Btu } / \mathrm{hr} \times 0.2931=\text { watt }
\end{aligned}
$$

* See also[1]. (Numbers in brackets designate References at end of report.) 
1. Introduction . . . . . . . . . . . . . 1

2. Specification . . . . . . . . . . . 3

3. Design Parameters . . . . . . . . . . 4

3. 1 Compression Equipment . . . . . . . . 4

3.2 Expander . . . . . . . . . . . 4

3. 3 Generator Dimensions. . . . . . . . 4

3.4 Weight . . . • . . . . . . . . 4

3. 5 Generator Operation . . . . . . . 5

4. Process and Design Limitations of the Air Separation

Process • . • . . . . . . . . . 5

4. 1 Introduction . . . . . . . . . . 5

4. 2 Allowable Space. . . . . . . . . 6

4. 3 Allowable Weight . . . . . . . . . 7

4. 4 Condition of Feed Air . . . . . . . . 8

5. Air Separation Process . . . . . . . . . 9 9

5.1 Introduction . . . . . . . . . . . 9

5.2 Process Description . . . . . . . . . 9

5.3 Data for Process Calculations . . . . . 12

6. Generator Operation . . . . . . . . . 12

6.1 Introduction . . . . . . . . . . 12

6.2 Generator Reactivation . . . . . . . 13

6. 3 Generator Startup . . . . . . . . . 13

6. 4 Normal Operation . . . . . . . . . 14

6. 5 Liquid Oxygen Production . . . . . . 15

6. 6 Liquid Nitrogen Production . . . . . . . 15

6.7 Controls for Automatic Operation . . . . . 16 
CONTENTS (Continued)

Page

6.7.1 Feed Air Flow Rate Control. . . . . 16

6.7.2 Product Purity Control . . . . . 16

6.7.3 Refrigeration Control . . . . . 18

6.7.4 Miscellaneous Generator Controls. . . 18

6.7.4.1 Level Controls. . . . . 18

6.7.4.2 Pressure Controls . . . 19

6.7.4.3 Temperature Controls. . . 19

6.7.4.4 Pressure . . . . . 19

6.7.4.5 Temperature . . . . . 19

6.7.4.6 Purity Analyzer . . . . 20

7. Impurity Removal • . . . . . . . . . . . 20

7. 1 Introduction . . . . . . . . . . . . . . 20

7.2 Impurity Removal At or Near Ambient

Temperature. • . . . . . . . . 21

7. 3 Impurity Removal by Liquefaction and

Solidification in a Heat Exchanger. . . . . . 25

7. 4 Impurity Removal in Regenerators and

Adsorbent Bed • . . . . . . . . 27

7.5 Choice of Purification System . • • . • • . 27

8. Distillation Columns • • • • • • • • • • • 28

8. 1 Introduction . . . . . . . . . . . 28

8. 2 High Pressure Column . . . . . • . . 28

8.3 Low Pressure Column . . . . . . . . . 29

9. Heat Exchanger Design . • . • . . . . . 30

9. 1 Introduction . . . . . . . . . . . 30 
CONTENTS (Continued)

Page

9.2 Heat Exchanger I . . . . . . . . 31

9.3 Heat Exchanger II . . . . . . . . 32

9.4 Subcooler . . . . . . . . . . 33

9.5 Condenser-Reboiler . . . . . . . 33

9. 6 Compressor and Blower Aftercoolers . . . . 33

9. 7 Refrigerant 12 Condenser and Air Cooler . . . 34

9.8 Defrost Heater . . . . . . . . . . 34

10. Machinery . . . . . . . . . . . . 34

10.1 Introduction . . . . . . . . . . . 34

10.2 Expansion Engine and Blower . . . . . . 35

10.3 Lobe-Type Blower . . . . . . . . 35

10.4 Refrigerant 12 System . . . . . . 35

10.5 Air Compressor. . . . . . . . . 36

10.6 Liquid Oxygen Pump . . . . . . . . 36

11. Insulation . . . . . . . . . . . . 37

11.1 Introduction . . . . . . . . . . 37

11.2 Column Cold Box . . . . . . . . . 38

11.3 Heat Exchanger Cold Box . . . . . . 39

11.4 Insulation of Purification System . . . . . 39

12. Physical Arrangement . . . . . . . . . . 40

12.1 Introduction . . . . . . . . . . 40

12. 2 Column Cold Box Arrangement. . . . . . 40

12. 3 Equipment Arrangement . . . . . . . 41

12. 4 Instrumentation and Controls . . . . . . 41

12.5 Power and Weight . . . . . . . . . 42

13. Conclusions and Recommendations . . . . . . 44

14. References . . . . . . . . . . . . 47 47 
Figure 1. Process Flow Diagram of the Liquid OxygenNitrogen Generator . . . . . . .

Figure 2. General Arrangement of the Water Knockout

Figure 3. Drier and $\mathrm{CO}_{2}$ Adsorber . . . . . .

Figure 4.

Impurity Removal through Liquefaction and

Solidification.

Figure 5. Cooling Curve of the Freezeout Heat

Exchanger . . . . . . . . 53

Figure 6.

Impurity Removal in Regenerators

Figure 7.

High Pressure Column Cross Section

Figure 8.

Column Cross Section Typical Tray

Figure 9.

Vapor-Liquid Equilibrium of Oxygen-Nitrogen for High Pressure Column . . . . . .

Figure 10. Vapor-Liquid Equilibrium of Argon-Oxygen-

Nitrogen System for Low Pressure Column. .

Figure 11. Low Pressure Column Cross Section. . .

Figure 12

Cooling Curve Heat Exchanger I .

Figure 13.

Cooling Curve Heat Exchanger II

Figure 14.

Vacuum Insulation for Column Cold Box. . .

Figure 15.

Column Coid Box Partial Elevation

Figure 16. Column Cold Box Elevation

Figure 17.

Column Cold Box Plan View.

Figure 18. Equipment Arrangement Plan View 


\section{LIST OF TABLES}

Page

Table 2.1 Contaminants in Feed Air . . . . . . 3

Table 4.1 Saturated Water Content of Air as a Function of Temperature ... . . . . . . . . . 8

Table 7. I Carbon Dioxide Content of Air as a Function of Temperature . . . . . . . . 26

Table 11.1 Performance of Various Insulation Systems . . 38

Table 12.1 Equipment Weight • . . . . . . . . 42

Table 12.2 Power Requirements . . . . . . . . 43 

Study of a Mobile Liquid Oxygen-Nitrogen Generator

$$
\begin{gathered}
\text { Peter C. Vander Arend, Stanley T. Stoy } \\
\text { and }
\end{gathered}
$$

Thomas R. Strobridge

It appears feasible to produce as much as 4 tons per day of liquid oxygen or liquid nitrogen of 99.5 percent purity with the equipment contained in an envelope $8 \mathrm{ft}$ by $8.5 \mathrm{ft}$ by $15 \mathrm{ft}$. The process cycle is completely described. Physical layouts were studied to assure that the equipment required for the modified process would fit into the allotted space. A conceptual layout of the cold components, with the required vacuum insulation, was developed.

Major modifications to the existing 2 ton per day generator consisted of: a) the use of a blower on the expansion engine to pressurize part of the air stream to 105 psia, b) the use of a liquid oxygen pump to move liquid from the sump of the low pressure column to the reboiler side of the reboiler condenser and c) the purification of feed air in a separate system before it joins the major recycle stream. It was assumed that a compressor would supply air to the process at the same pressure and flow rate as the existing unit.

Key words: Air separation; liquid nitrogen; liquid oxygen; mobile; purification.

\section{Introduction}

A number of mobile liquid oxygen-liquid nitrogen generators are in use by the U.S. Navy $[2,3]$. These generators produce approximately 2 tons per day of liquid oxygen. A previous study car ried out by the Cryogenics Division of the National Bureau of Standards [4] concluded that within the envelope of the existing generator and with its air supply, a considerable increase in the liquid oxygen or nitrogen production might be possible. 
The present study deals in more detail with the engineering aspects of the mobile liquid oxygen-liquid nitrogen generator. It has been assumed that the air supply conditions and equipment envelope have remained unchanged. Various processes were studied to optimize the available refrigeration. Additional refrigeration has been added in the form of a Refrigerant $12(R-12)$ system.

Available height was found to be a severe limitation on the low pressure column performance. Because only a limited number of trays can be installed, it is impossible to separate air completely into pure streams of oxygen and nitrogen. The nitrogen leaving the top of the low pressure column contains approximately $5-6$ percent oxygen.

In order to make full use of the limited height, the low pressure column stretches the full height of the envelope. A liquid oxygen pump lifts liquid oxygen from the bottom of the low pressure column to the reboiler-condenser located on top of the high pressure column.

To improve the thermodynamic efficiency of the process, work available from the expansion engine is used to compress some of the process air to approximately $105 \mathrm{psia}$. This makes it possible to operate a high pressure column, reboiler-condenser, and low pressure column in accordance with standard industrial practice.

Purification of the feed air to the generator is carried out near ambient temperature before it joins the recycled air of the process. Most of the water present in the air is condensed in a R-12-air heat exchanger. The remaining water vapor and carbon dioxide are removed from the air stream in a desiccant bed. Trace impurities consisting of components with low boiling points not removed in the purification system are carried in the air to regions of low temperature 
in the plant. The se impurities settle out in the liquefied air and finally find their way to the liquid oxygen sump in the low pressure column. A guard adsorber located down stream of the sump removes these impurities.

\section{Specification}

The oxygen-nitrogen generator must produce liquid oxygen and nitrogen meeting the following specifications:

Oxygen Purity:

Nitrogen Purity:
99.5 percent as per MIL-O-27210B

99.5 percent as per MIL-N-6011

Air supplied to the plant will be at the following conditions:

Pressure:

One Standard Atmosphere

Temperature: $\left(-30^{\circ} \mathrm{F}\right.$ to $\left.+125^{\circ} \mathrm{F}\right)$

Contaminants in the feed air to the generator are not to exceed the limits shown in Table 2.1.

\section{Table 2.1}

Contaminants in Feed Air

Water

Argon

Carbon Dioxide

Nitrous Oxide

Carbon Monoxide

Methane

Sulfur Dioxide

Acetaldehyde
Saturated

$10,000 \mathrm{ppm}$

$1000 \mathrm{ppm}$

$5 \mathrm{ppm}$

$20 \mathrm{ppm}$

3 ppm

$1 \mathrm{ppm}$

$1 \mathrm{ppm}$ 


\section{Design Parameters}

\subsection{Compression Equipment}

The basic choice of compression equipment is between high pressure reciprocating or low pressure rotating machinery; the existing oxygen generator employs rotating machinery. This study assumes the use of rotating machinery since it is available and relatively light in weight. It also assumes that the compressor can recycle purified air in a closed loop and that feed air may be purified before it joins the air of the closed loop.

\subsection{Expander}

When low pressure compression equipment is used, the refrigeration must be provided by a turbo expander. A reciprocating machine would be too bulky and operate at too high a speed to be reliable. Turbo expanders are standard devices and it is possible to design the process before selecting the expansion engine. The expansion engine specification is determined by the process design of the generator.

\subsection{Generator Dimensions}

The generator is to fit an envelope of the following dimensions:

$\begin{array}{ll}\text { Height } & 8.5 \mathrm{ft} \\ \text { Width } & 8 \mathrm{ft} \\ \text { Length } & 15 \mathrm{ft}\end{array}$

\subsection{Weight}

Maximum weight is not specified. 


\subsection{Generator Operation}

The generator, after manual startup, will operate in a semi-automatic mode. The generator will operate automatically in the steady state with product purity and refrigeration control regulated by plant instrumentation. Major upsets caused by malfunctioning machinery will shut down the generator. Personnel attendance will be required for startup, shutdown, evaluation of the reason for shutdown, and to monitor machinery and instruments. No auxiliary fluids will be required.

\section{Process and Design Limitations of the Air Separation Process}

\section{1 Introduction}

Separation of air into its components through low temperature distillation is a well-known process and is treated in a number of standard texts $[5,6]$. The low temperature industry has developed a number of processes by which air is separated into its components. Historically, major changes have come about through technological developments in certain areas. In the early days, high pressure processes were used extensively to produce the necessary refrigeration without expansion engines. Low pressure processes were developed when rotating compressors and turbo expanders became available.

Various methods of air purification have been used. Adsorption at high and low temperatures and freezeout by deposition of the solid material on heat exchanger or regenerator surfaces have all been employed. 
In general, the choice of process, including purification of the feed air, is based on overall economic considerations. Production of liquid oxygen or nitrogen at lowest overall cost may result in a process which thermodynamically is not the most efficient and does not show the lowest horsepower per unit of production.

The process and design of the mobile oxygen-nitrogen generator in this study is greatly influenced by the allowable space and weight of the complete unit, the condition of the feed air to the generator, and the compression equipment used.

\subsection{Allowable Space}

Air separation plants normally are not limited in height. In order to separate air into its components by distillation, a double column with a reboiler-condenser is used. The equipment is arranged in a single column with the low pressure column at the top, the high pressure column at the bottom, and the reboiler-condenser between the low and high pressure columns. The number of trays used in both columns is set by the requirements of the process, and generally the column assembly is very much taller than the height allowed for the mobile generator.

In order to stay within the allowable height, the following must be done:

a) The low and high pressure columns are placed side by side. The reboiler-condenser may be located on top of the high pressure column or at the bottom of the low pressure column. 
b) Regardless of the location of the reboiler-condenser, a liquid pump is required. When the reboiler condenser is at the bottom of the low pressure column, liquid nitrogen must be pumped from the condensing side to the top of the high pressure column to provide reflux for that column. If the reboiler-condenser is at the top of the high pressure column, then liquid oxygen must be pumped from the sump of the low pressure column to the reboiler side.

c) The trays in the low pressure column must be as close together as is practical and feasible.

\subsection{Allowable Weight}

Although maximum weight is not specified, the expression "mobile generator" implies the requirement of moving the generator with reasonable ease. This means that the weight cannot be indiscriminately high. The selection of rotating machinery results in lowest weight and unbalanced forces for compressor and expander. With a rotary compressor, the pressure attainable is relatively low. This affects the process from a standpoint of refrigeration available at the lowest temperature levels. Refrigeration through efficient expansion of air in a centrifugal expander may be obtained at higher temperature levels.

In order to produce liquid oxygen efficiently, a considerable amount of refrigeration must be made available to the low pressure column at the lowest temperature level in the generator. Section 5 deals with this subject in more detail. 
The condition of the feed air to the generator is important for the determination of weight and size of the purification system. Most important, the specification of Section 2 states that the air entering the generator may be as high as $125^{\circ} \mathrm{F}$ in temperature and saturated with water vapor. The amount of moisture contained by air in the saturated condition is shown as a function of temperature in Table 4.1. The table shows that air saturated at $125^{\circ} \mathrm{F}$ will require a large amount of refrigeration for the condensation and removal of water from the air.

\section{Table 4.1}

Saturated Water Content of Air as a Function of Temperature

$\begin{array}{cc}{ }^{T}{ }_{\mathrm{F}} & \text { Water Content of Air } \\ & \text { Moles per Mole of Air } \\ 125 & 0.1530 \\ 120 & 0.1310 \\ 110 & 0.0955 \\ 100 & 0.0695 \\ 90 & 0.0503 \\ 80 & 0.0359 \\ 70 & 0.0255 \\ 60 & 0.0179 \\ 50 & 0.0123 \\ 40 & 0.0084 \\ 30 & 0.00555 \\ 20 & 0.00346 \\ 10 & 0.00218 \\ 0 & 0127\end{array}$




\section{Air Separation Process}

\subsection{Introduction}

A considerable amount of process work was done during the course of this study in order to increase the output of the liquid oxygennitrogen generator. In order to satisfy the conditions of limiting height and rotating compression equipment, the process calculations were repeated a number of times before the final cycle was selected. For instance, the initial process employed a liquid nitrogen pump to return the condensed nitrogen from the reboiler-condenser to the top of the high pressure column. As a result of actual design of the low pressure column and reboiler-condenser, it became necessary to make the low pressure column as tall as possible, leaving no space available for the reboiler-condenser at the bottom of the low pressure column. By pumping liquid oxygen instead of liquid nitrogen, the reboiler-condenser may be located at the top of the high pressure column allowing maximum height for the low pressure column.

The diameter of the low pressure column was increased in the final stages of the study when it became apparent that the desired number of trays could be fitted in the low pressure column only by decreasing vapor velocities and reducing the distance between individual trays.

\subsection{Process Description}

Figure 1 shows the process schematic of the oxygen-nitrogen generator. Air is drawn in by a blower (stream 1) and compressed (stream 2) sufficiently to overcome the pressure drop in the R-12-air heat exchanger and adsorber vessels. The air is cooled to approximately $40^{\circ} \mathrm{F}$ in the $\mathrm{R}-12$-air heat exchanger where most of the water vapor is 
condensed. The liquid water is separated from the air stream in the knockout vessel. Water saturated air at $40^{\circ} \mathrm{F}$ enters one of the two adsorber vessels (stream 4). These vessels are filled with a desiccant in which both water and carbon dioxide are adsorbed. Impurities other than water and carbon dioxide will pass into the main recycle stream (6) of the generator. Most of the impurities will liquefy in the air stream (14) or in the reboiler-condenser of the generator. Finally, these impurities will find their way into the liquid oxygen and will be removed in the guard adsorber located in stream (19). The compressor recycles air made up of a new feed air (stream 5) plus pure air coming from the expansion engine discharge via the heat exchangers (stream 37 ). The air is compressed to $80 \mathrm{psia}$ and the heat of compression is removed in the aftercooler. The aftercooler may be air or water cooled.

The compressed air is divided into three streams. The largest part (stream 33) flows through exchanger I to the expansion engine and returns as a low pressure stream (37) through exchangers I and II to the suction of the compressor. This stream provides the refrigeration required for cooling and liquefying the product of the generator. A second stream (38) flows through exchangers I and II with very little pressure drop and is liquefied in exchanger II. This stream provides some of the reflux and all of the refrigeration required to operate the low pressure column. A third stream (8) flows to the suction of the blower and is compressed by the blower to a pressure of 105 psia. This air is cooled in exchangers I and II to its saturation point $\left(-274^{\circ} \mathrm{F}\right)$ and flows to the high pressure column (stream 11).

Separation of the air into its components begins in the high pressure column. Refrigeration required by the high pressure column is supplied by an indirect route. Stream 13 is liquefied through heat 
transfer to the expander discharge stream (35). (Recall that the expander produces all of the cooling for the entire process.) After passing through a control valve, the low temperature, low pressure (stream 14) fluid is fed to the low pressure column. Pure liquid oxygen is produced in the sump of the low pressure column. Part of that liquid oxygen is pumped to the reboiler-condenser at the top of the high pressure column. There, since the expander blower is used to produce the 100-105 psia operating pressure in the high pressure column; nitrogen condenses on one side of the exchanger as the oxygen boils on the other. The high pressure is necessary to condense the nitrogen at the temperature of the oxygen. The liquid nitrogen flows down the high pressure column and the oxygen vapor is returned (stream 39) to the sump of the low pressure column and starts to flow upward.

The liquid stream leaving the bottom of the high pressure column is essentially in equilibrium with the gaseous air entering the column (stream 11) and contains approximately 36 percent oxygen (molar basis). Some of the condensed nitrogen leaves the high pressure column (stream 25) and becomes reflux for the top of the low pressure column (stream 27). This liquid is subcooled in the subcooler through heat exchange with the vapor leaving the top of the low pressure column (stream 17). Also, when liquid nitrogen is produced by the generator, the product nitrogen will be taken off after passing the subcooler (stream 26).

Pure liquid oxygen from the bottom of the low pressure column is removed from the generator after subcooling against cold nitrogen vapor to reduce the flashing losses in the storage container receiving the liquid (stream 21). Waste nitrogen gas leaves the top of the low 
pressure column (stream 17). This waste nitrogen gas contains, in addition to some oxygen, all of the argon present in the air fed to the columns. In addition to the impurities listed in the specification, the air fed to the columns also contains some neon, hydrogen, and helium. These gases will not condense at $-320^{\circ} \mathrm{F}$, and if allowed to accumulate in the generator, will finally prevent normal operation of the condenser-reboiler. To prevent accumulation, a small bleed stream is taken off the condenser and vented to the atmosphere.

\subsection{Data for Process Calculations}

Data required for the calculations are:

a) Thermodynamic data for air, nitrogen, oxygen, and mixtures of nitrogen and oxygen $[7,8]$.

b) Vapor-liquid equilibria data for mixtures of nitrogen oxygen and argon at the pressures of the high and low pressure columns $[9,10]$.

c) Distillation column tray design data $[11,12]$.

d) Heat transfer correlations for gases, boiling liquid, and condensing vapors [13].

e) Pressure drop correlations for flow of gases and liquids $[14]$.

f) Performance data for insulation [15].

\section{Generator Operation}

\section{1 Introduction}

Figure 1 shows schematically various control valves and instruments; their selection and particular location in figure 1 are the result of "operating" the generator on paper. The following sections deal with the various phases of generator operation. 


\subsection{Generator Reactivation}

The generator will be started only after a thorough drying of all the low temperature components and reactivation of at least one of the adsorber vessels for removal of water vapor and carbon dioxide.

To begin reactivation of the generator, the lobe blower and air compressor are started. By closing the valves in streams 9, 33, and 38 , the compressor discharge stream is forced to recycle through the pressure control valve between lines 32 and 37 .

Some gas is taken from the compressor discharge at point A before it has passed through the aftercooler. This warm gas is fed to line 9 (point $\mathrm{A}^{\prime}$ ) and warms successively heat exchangers I, II, and the high pressure column before venting through the liquid nitrogen product line. By opening the throttle valve in line 15, warm gas enters the low pressure column. The flow divides two ways: one part flows through lines 18, 19, 20, 21, and 39 to a vent and the liquid oxygen product line; the other part flows through lines 17, 27, and 29 to the nitrogen vent line and the liquid nitrogen product line.

The rate of gas flow during the reactivation process is less than the feed flow to the generator during steady state operation. The feed gas is dried in the warm purification section of the generator before it enters the air compressor system. Reactivation of the other drier may be achieved in the normal manner by providing some gas to the heater from stream 31 .

\subsection{Generator Startup}

The generator will be started only after a thorough reactivation process in accordance with Section 6.2 has been carried out and a reactivated adsorber for water and carbon dioxide removal is available. 
The lobe blower and compressor are started and air begins to flow to the expansion engine through line 33. The blower of the expansion engine will compress air from stream 8 . This air will be returned to the suction of the blower through the bypass valve between lines 9 and 32 until flow to the high pressure column is started.

When the discharge of the expander (stream 35) becomes cold, flow through lines $38,12,13$, and 14 into the low pressure column will be started. Gas from the low pressure column is vented through lines 29 and 31 . The high pressure column is cooled with gas flowing through lines 9, 10, and 11 . The gas is vented from the high pressure column to the low pressure column through lines 15, 25, 26, and 27 .

With time, liquid starts to accumulate in the low pressure column. When sufficient liquid is in the bottom of the column, the liquid oxygen pump is started and condensation will start in the reboiler-condenser. The flows through lines 15 and 25 are adjusted to accumulate liquid in the high pressure column.

\subsection{Normal Operation}

To reach the required purity of the oxygen product in the low pressure column, the system will be operated at low capacity after liquid levels have been established in both the high and low pressure columns. The flow of liquid from the high pressure to the low pressure column is not automatically controlled. The valve in line 15 acts as an orifice and initially this valve will be throttled to a low flow rate. Next, the temperature controller in line 35 is activated. The temperature of the expander discharge gas (stream 35) will be controlled manually by venting gas from line 29 directly to the atmosphere. This will continue until the liquid oxygen in the low pressure column sump becomes pure. Depending on the rate of venting from line 29, some 
impure product may have to be delivered to the product line (2l) and vented away.

Once the required oxygen purity in the low pressure column is obtained, the manual throttle valve in line 15 will be opened to its normal steady state condition and excess liquid nitrogen will flow as reflux (line 27) into the low pressure column. This flow rate is controlled by a liquid level sensor in the sump of the high pressure column. Product oxygen will flow from the generator through a valve controlled by the level sensor in the sump of the low pressure column. Rate of production is controlled by the temperature controller in line 35 .

\subsection{Liquid Oxygen Production}

The procedure described in Section 6.4 is used to produce liquid oxygen only. The liquid nitrogen made in the reboiler-condenser is used completely for reflux to the high and low pressure columns.

\subsection{Liquid Nitrogen P roduction}

In order to produce liquid nitrogen, the valve in the generator product nitrogen line 28 is opened. This will automatically reduce the flow of liquid nitrogen to the top of the low pressure column and the level controller in the sump of the low pressure column will reduce the flow of liquid oxygen to line 21. P roduct oxygen purity will be maintained since the liquid-to-vapor flow ratio in the low pressure column will be reduced. By varying the rate of liquid nitrogen withdrawal, the ratio of liquid oxygen to liquid nitrogen production may be controlled at will. 


\subsection{Controls for Automatic Operation}

The flow diagram in figure 1 shows that only the purification system at the warm end of the generator is operated manually. Depending on the water content of the feed air and rate of production, the adsorber vessels will be switched manually at intervals of 2-6 hours. The length of interval will be determined by checking for breakthrough of the impurities in the adsorber bed at certain sample points.

All other controls of the generator operate automatically once the plant has been started and brought to equilibrium and full production. The controls operate as follows:

\subsubsection{Feed Air Flow Rate Control}

A valve in line 2 allows air to vent back to the atmosphere when the pressure in the discharge of the blower becomes too high.

\subsubsection{Product Purity Control}

Because of the limitation in height of the low pressure column and the limited number of trays in this column, liquid oxygen purity control is critical. The low pressure column is designed to produce the required product purity when the reflux ratio in the low pressure column is maintained at or below a design level. The reflux ratio in the bottom of the low pressure column is controlled by the division of flow between streams 11 and 14. The stream 11 flow rate determines the rate of oxygen vapor generation for the bottom of the low pressure column since all of the nitrogen in stream 11 is eventually condensed at the top of the high pressure column. When the generator produces liquid oxygen only, all of stream 11 becomes liquid and is fed ultimately to the low pressure column as streams 15 and 27. The total liquid flow 
to the low pressure column is the sum of streams 14, 15, and 27. With stream 11 fixed, only stream 14 may be varied to change the liquid flow rate to the low pressure column.

The reflux ratio of the column is determined by the ratio of flow of streams $15+27+14$ and 11 . If the reflux ratio is too high and the required purity of the oxygen is not obtained, stream 11 flow may be increased and stream 14 flow decreased. Ultimately the flow rate of stream 11 is fixed by the expander-blower capacity, therefore, variation of the reflux ratio is only possible by variation of stream 14. If purity of the oxygen product is satisfactory, stream 14 flow will increase until the temperature controller in stream 35 indicates that all of the available refrigeration is being used. This is the point of maximum production of the generator.

If the required purity cannot be obtained under these conditions, the differential temperature controller in the low pressure column will reduce stream 14 in an indirect way by opening a bypass valve in the nitrogen vent off line 29. When this valve opens, refrigeration is wasted and stream 14 will be reduced to maintain the proper discharge temperature of the expander. The signal for operation of the bypass valve is produced from the measurement of the difference of temperature of two points in the low pressure column. Under normal operating conditions, each tray of the low pressure column has a characteristic composition, and with it, a characteristic temperature. This temperature is pressure dependent. By measuring the differential temperature of two points, the pressure dependence is eliminated. A change in the characteristic temperature will be detected well before the purity of the oxygen product in the bottom of the low pressure column drops below the specified value. Corrective action is taken automatically and the upset will not reach the bottom of the low pressure column. 


\subsubsection{Refrigeration Control}

If the generator is equipped with a sufficient number of trays in the low pressure column to produce the required purity within a range of reflux ratios, refrigeration control becomes the primary control of the generator. Refrigeration is provided by the expander. Excess refrigeration manifests itself in lowering the expander discharge temperature, and lack of refrigeration has the opposite reaction. The valve in stream 14 will be controlled as a function of expander discharge temperature for maximum liquid production.

\subsubsection{Miscellaneous Generator Controls}

In addition to the product purity and refrigeration controls, other controls which make the operation of the generator semiautomatic are:

\subsubsection{Level Controls}

The sump of the high pressure column receives liquid from the top of the column and delivers liquid to the low pressure column through line 15 and its manual valve. The manual valve is set and acts as a fixed orifice. The setting is not very critical, but should be based on operational experience with the plant running at full capacity. The valve in line 27 is controlled by the level controller in the sump of the high pressure column to add the proper quantity of reflux liquid nitrogen to the top of the high pressure column. The flow of liquid oxygen from the sump of the low pressure column is controlled by a level controller which acts on the liquid oxygen product valve. 


\subsubsection{Pressure Controls}

The low pressure column pressure is controlled by a valve in the discharge of the waste gas (line 31 ). This control valve operates the low pressure column at constant pressure and at the same time provides a bleed stream for the reactivation of the adsorbers. The air compressor has a bypass control valve activated by a pressure sensor in the discharge line of the compressor. This controller and valve allow operation of the compressor without running the expander or other parts of the plant. A valve in line 2 opens to the atmosphere if the lobe-type air blower discharge pressure becomes too high; therefore, the blower can be independently operated.

\subsubsection{Temperature Controls}

The $\mathrm{R}-12$ refrigeration system is controlled by maintaining a constant temperature of the feed air stream at the inlet to the knockout drum. The control normally is a pressure control in the $R-12$ evaporator since each temperature has a fixed related pressure.

\subsubsection{Pressure}

Pressure is measured in a number of the process streams to ascertain that the generator is operating normally. Excessive pressure drop, especially in the high pressure circuits, will indicate when impurities break through the cleanup system and freeze out in the heat exchangers.

\subsubsection{Temperature}

Temperature measurement of the streams in and out of the heat exchangers will also indicate freezeups. 


\subsubsection{Purity Analyzer}

The oxygen content of the waste stream (line 29) and the product streams will be monitored.

\section{Impurity Removal}

\section{1 Introduction}

The composition of the air, including impurities, is fixed, except for the water content. The specification given in Section 2 states that the air entering the generator can be saturated with water vapor and that the temperature of the air may vary from $-30^{\circ} \mathrm{F}$ to $+125^{\circ} \mathrm{F}$. Table 4.1 shows the amount of water in air as a function of temperature. At the upper temperature limit of $125^{\circ} \mathrm{F}$, some 9.72 moles of water need to be removed per hour from the feed air stream of 63.7 moles $/ \mathrm{hr}$.

Refrigeration is required to remove the water and carbon dioxide from the feed air. When the contaminants are removed as vapor, the heat of adsorption must be removed. If the air is cooled before adsorption of the water vapor is accomplished, a large part of the water is condensed in the cooling process. In that case, the heat of vaporization (condensation) must be removed in the cooling process.

There are three basic ways in which the main contaminants of water and carbon dioxide may be removed from the air:

a) Cooling the air with an R-12 refrigeration system, followed by physical separation of liquid water and adsorption of the remaining water vapor and carbon dioxide on a desiccant bed at approximately $40^{\circ} \mathrm{F}$. 
b) Cooling the air by heat transfer to a low temperature refrigeration stream and successive removal of water and carbon dioxide by liquefaction and solidification in the heat exchanger. The liquefied and solidified material finally will be removed by a purge stream of dry waste gas from the generator.

c) Cooling the air in regenerators so that most of the impurities solidify, combined with some removal of carbon dioxide in adsorber beds operating at -230 to $-240^{\circ} \mathrm{F}$.

Each of the above methods have advantages and disadvantages. Sections $7.2,7.3$, and 7.4 deal with each of the methods.

\subsection{Impurity Removal at or Near Ambient Temperature}

The system chosen to remove water and carbon dioxide from the feed air is shown schematically in figure 1 . The feed air is cooled to a temperature of $40^{\circ} \mathrm{F}$ by Refrigerant 12 evaporating at $30-35^{\circ} \mathrm{F}$. The duty of the exchanger (the amount of heat to be transferred) is a function of the air flow rate and the heat content of the air at inlet and outlet (streams 2 and 3). When air of $125^{\circ} \mathrm{F}$ is fed to the generator, the lobe-type blower will discharge the air at a temperature of $161^{\circ} \mathrm{F}$. Cooling the air from a temperature of $161^{\circ} \mathrm{F}$ and a dew point of $125^{\circ} \mathrm{F}$ to $40^{\circ} \mathrm{F}$ (saturated) requires removal of $212,000 \mathrm{Btu} / \mathrm{hr}(63.7 \mathrm{moles} / \mathrm{hr}$ of dry air feed stream). Of this amount $156,500 \mathrm{Btu} / \mathrm{hr}$ is contributed by the condensation of water. If the air fed to the generator has a dew point of $90^{\circ} \mathrm{F}$ and a temperature of $125^{\circ} \mathrm{F}$, the R-12-air cooler need only remove $97,600 \mathrm{Btu} / \mathrm{hr}$. 
It is obvious that the R-12 refrigerator primarily functions to condense water. The R-12 system required to dry air with a dew point of $125^{\circ} \mathrm{F}$ is approximately twice the size of that necessary to condense water from air with a dew point of $90^{\circ} \mathrm{F}$. In order to assure that all generator equipment fit the stipulated maximum envelope of $8 \mathrm{ft}$ by $8.5 \mathrm{ft}$ by $15 \mathrm{ft}$, it has been assumed that the feed air will have a maximum dew point temperature of $90^{\circ} \mathrm{F}$.

After the air has been cooled to $40^{\circ} \mathrm{F}$ the liquid water is separated in the knockout vessel. The diameter of this vessel is large enough to separate the water droplets from the air stream and to collect them in the bottom of the vessel. A liquid level controlled valve will drain water from the vessel.

The diameter of the vessel is determined from laws applicable to particle motion in a gas atmosphere under the influence of gravity. A number of textbooks on this subject are referred to in [12]. The general expression for maximum permissible air velocity in an upward direction under which spherical fluid particles will settle is as follows:

$$
U=K_{V}-\frac{L-g}{g} \quad \text { in consistent units }
$$

where $\quad U=$ air velocity in $\mathrm{ft} / \mathrm{sec}$

$L=$ density of water in $1 \mathrm{~b} / \mathrm{ft}^{3}$

$g=$ density of air in $1 \mathrm{~b} / \mathrm{ft}^{3}$

$\mathrm{K}_{\mathrm{V}}=$ coefficient in $\mathrm{ft} / \mathrm{sec}$.

The value of $\mathrm{K}_{\mathrm{V}}$ is normally chosen to be approximately 0.2 $\mathrm{ft} / \mathrm{sec}$. With this value, the diameter of the knockout vessel will be about $1.3 \mathrm{ft}$. 
The general arrangement of the knockout vessel is shown in figure 2. The wet gas enters tangentially above the internal baffle. The water droplets are slung against the wall of the vessel and the initial motion of air and water is downward. At the bottom of the baffle the air flow turns upward and flows out of the vessel through the center exit pipe. Water collects in the bottom of the vessel. Dimensions other than the diameter of the vessel are chosen on the basis of practical experience.

After the bulk of the liquid water has been removed, the saturated air at $40^{\circ} \mathrm{F}$ flows to one of two parallel ves sels containing a desiccant. Design practice in industry normally assumes that some liquid water in the form of very small droplets will be carried beyond the knockout vessel. The amount chosen is set somewhat arbitrarily, and in this case, was assumed to be 15 percent of the amount of water carried in the saturated air. Table 4.1 shows that saturated air of $40^{\circ} \mathrm{F}$ contains 0.0084 moles of water vapor per mole of dry air. The desiccant beas, therefore, have to remove water vapor at a rate of $1.15 \times 0.0084 \times 63.7=0.616 \mathrm{moles} / \mathrm{hr}$.

In order to save space, type 13X, molecular sieve desiccant will be used; this material will remove both water and carbon dioxide from the feed air. The capacity of the desiccant for water and carbon dioxide vapor under various operating conditions is supplied by the manufacturers of these materials. The design of the adsorber vessel with regard to diameter, height, and method of reactivation was based on data also supplied by the manufacturers.

The pressure drop through the bed determines the minimum diameter. If the flow of air is upwards, then the pressure drop must not exceed that value which would lift the particles and fluidize the bed. The air flow, therefore, is normally downward. 
Not all of the desiccant is fully utilized for the removal of the water and carbon dioxide. In order to purify the air to a level of a few parts per million the bed must have a concentration gradient between inlet and discharge conditions. The length of bed used for this gradient is a few feet.

Since water is preferentially adsorbed by the molecular sieve, the entrance of the bed will contain all of the water and the downstream part of the bed will contain the carbon dioxide. With time, the water replaces the carbon dioxide, and if the bed is used too long, the first impurity to appear in the air leaving the bed will be carbon dioxide. In order to utilize the bed fully, a few sample points will be located inside the bed at short distances from the discharge end of the bed. Breakthrough of impurities at these sample points will warn the operator that a limited amount of time is left in the adsorption cycle of the bed.

After the desiccant has been fully utilized, impurities are driven off by passing dry gas with a temperature of $500^{\circ} \mathrm{F}$ in the opposite direction to air flow through the bed. The gas used for this purpose is waste gas from the generator (stream 31). The total amount of heat required to heat the bed, wall, and desiccant and to vaporize water and carbon dioxide is some 130,000 Btu. To supply this amount of heat in a period of $2 \mathrm{hr}$, an electric heater with a capacity of $65,000 \mathrm{Btu} / \mathrm{hr}(20 \mathrm{KW})$ is required. The rate of flow of waste gas during the reactivation period is 19 moles per hour. Approximately 50 percent of the reactivation time is used for heating and 50 percent for cooling to ambient temperature. Cooling is accomplished simply by turning off the electric heater and continuing the flow of waste gas. Figure 3 shows the general arrangement of the adsorber vessel. 


\subsection{Impurity Removal by Liquefaction and Solidification in a Heat Exchanger}

Figure 4 shows the flow schematic of a set of heat exchangers in which water and carbon dioxide are removed from the feed air through liquefaction and solidification. The system is a modification of the purification system discussed in [16]. The dark lines show the flow of gas when exchanger $A$ is being used for $r$ emoval of the impurities. Exchanger $B$ is being reactivated with waste gas from the generator. Feed air from the lobe-type blower enters exchanger A at the bottom. Cooling and liquefaction of water occurs in the bottom section of the exchanger. Liquid water will, with proper design of the heat exchanger, rundown into the warm bottom of the exchanger and accumulate. At temperatures of $32^{\circ} \mathrm{F}$ and lower, water will freeze out and be deposited as snow on the walls of the exchanger. At still lower temperatures the carbon dioxide will settle out as snow. At the cold end of the exchanger the purified gas is mixed with the cold gas from the expander discharge, flows through the return passages of the exchanger and on to the suction of the compressor.

In order to prevent plugging heat exchangers I and II (figure 1), it is necessary to lower the carbon dioxide content of the air to at least 5 ppm. Table 7.1 gives the equilibrium concentration of carbon dioxide in air at various temperatures showing that the air must be cooled to $-260^{\circ} \mathrm{F}$ to reach $5 \mathrm{ppm}$. The refrigeration required to condense the impurities and to make up for the losses in the heat exchanger is supplied by cold gas from the expander discharge. The flow rate needed is determined by the moisture content of the feed air.

The cooling curves of exchanger A or B under normal operating conditions are shown in figure 5 . 


\section{Table 7.1}

Carbon Dioxide Content of Air as a Function of Temperature

$\begin{array}{cc}\begin{array}{c}\text { Temperature } \\ { }^{\circ} \mathrm{F}\end{array} & \begin{array}{c}\mathrm{CO}_{2} \text { Content of Air } \\ \text { Parts Per Million of } \mathrm{CO}_{2}\end{array} \\ -225 & 320 \\ -230 & 190 \\ -240 & 60 \\ -250 & 17 \\ -260 & 5\end{array}$

Curves I and II are for air with a dew point of $125^{\circ} \mathrm{F}$ and a temperature of $161^{\circ} \mathrm{F}$ at the inlet of the heat exchanger. The flow rate from the expander is 1.142 moles per mole of feed air. Curves III and IV are for air with a dew point of $90^{\circ} \mathrm{F}$ and the same inlet temperature. In this case, 0.442 moles of expander discharge air are required per mole of feed air. Both the curves in figure 5 and the cold air flow rates demonstrate the increase in cooling requirement as the dew point increases.

The expander must operate at low temperature so that the column will function. Using part of the expander discharge stream for feed air purification is thermodynamically inefficient because the temperature is lower than necessary. The result, compared to the $\mathrm{R}-12$ system, is a reduction in liquid oxygen production of 10 percent if the dew point is $90^{\circ} \mathrm{F}$ and 22 percent if the dew point is $125^{\circ} \mathrm{F}$. The reduction in generator capacity would actually be somewhat larger since the heat exchangers would have to be cooled after each reactivation. 


\subsection{Impurity Removal in Regenerators and Adsorbent Bed}

Figure 6 shows the flow schematic of the regenerator cleanup system of the existing liquid oxygen-nitrogen generator [2].

Successful operation of the regenerator system depends on some liquid water removal after the air has been compressed. The regenerator contains a mass of solid material with large surface area. The amount of mass determines the length of time during which the regenerator can remove impurities. In order to maintain the required temperature gradient regardless of the number of cycles, part of the impure air flowing through the regenerator is removed before it reaches the cold end of the regenerator. Final purification of this bleed air is accomplished in an adsorber. A guard adsorber is used to remove trace quantities of impurities from the air flowing to the cold end of the regenerator.

The refrigeration required to freeze the water is obtained from the expansion turbine. Therefore, the generator employing a regenerator purification system will have a lower production capacity than a generator employing a separate R-12 refrigeration system and warm adsorbers.

\subsection{Choice of Purification System}

The objective of the study is to maximize the production capacity of the generator within a given envelope and with the assumed air supply. The use of the purification system employing R-12 refrigeration and adsorption equipment operating at $40^{\circ} \mathrm{F}$ will result in the highest production capacity of the generator. 


\section{Distillation Columns}

\section{1 Introduction}

Since the compressor flow and pressure were fixed through the use of an available component, it was necessary to determine the proper balance between flow required for separation and that required to provide the necessary refrigeration for the separation process. In addition, the space requirement imposed by the envelope size places a serious limitation on the number of trays that can be used in the low pressure column. Calculations to satisfy the material and energy balances around the columns and total generator resulted in the process conditions shown on the flow sheet. In order to use a conventional double column design utilizing a condenser-reboiler, it is necessary to raise the high pressure column pressure above the 80 psia available from the air compressor to provide a sufficient temperature difference between the condensing nitrogen vapor and boiling liquid pxygen. By using the air blower which dissipates the work of expansion of the turbine expander, air for the high pressure column is compressed to 105 psia. The high and low pressure columns were designed for pressures of 100 and 22 psia, respectively.

\section{2 High Pressure Column}

Since there is no appreciable argon enrichment in the high pressure column, it is possible to use the McCabe-Thiele Diagram [17] for the binary mixtures of oxygen-nitrogen to make the separation process calculations. The column design is based on sieve tray columns. Available data for sieve tray performance in low temperature separation processes [18] provide the required information to 
properly size and design columns. Figure 7 shows a schematic high pressure column design. Figure 8 shows a typical tray configuration for the column.

From the vapor-liquid equilibrium data for the oxygen-nitrogen system (figure 9) and the process conditions, the theoretical number of trays required for the high pressure column was determined to be 15. Overall tray efficiency for a high pressure column sieve tray operating with a 1 in unaerated liquid depth will be 100 percent [18]. Consequently, the actual number of trays will be 15 . Performance data available from low temperature sieve columns [18] show that the column diameter for a 3 in tray spacing is 12 in. Providing adequate space for the vapor outlet line, the feed line and the liquid outlet line, and adequate liquid holdup in the bottom of the column results in an overall column height of $67 \mathrm{in.}$

\subsection{Low Pressure Column}

The design of the low pressure column is seriously affected by available height and refrigeration. The argon-oxygen-nitrogen equilibrium data in figure 10 show that at high oxygen concentrations the effect of argon on the separation process becomes very pronounced.

To produce liquid oxygen of the required purity, the reflux ratio in the bottom of the low pressure column must be low. The maximum value is determined by the limited number of trays which can be installed in the available height of the column. In order to obtain a low reflux ratio, the rate of oxygen vapor generation in the bottom of the column should be high. This is difficult to do with a process in which the highest pressure available is 100 psia. 
The low pressure column must be refrigerated with either liquid air or nitrogen. To maximize the liquid oxygen production, liquid air and/or nitrogen flow must be high. The two requirements of low reflux ratio and high refrigeration supply need to be balanced carefully when the number of trays is limited and the highest pressure available is $100 \mathrm{psia}$. Insulation of the low pressure column is very important. Heat leak will reduce the output of the generator directly.

A maximum of 33 trays can be installed in the height available for the low pressure column. Tray spacing is then $2.6 \mathrm{in}$. The efficiency of the tray with 1.0 in of unaerated liquid is of the order of 80 percent. The theoretical number of trays is then 26 and the reflux ratio in the bottom of the column is 1.28. The process data given in the table of figure 1 just allow this reflux ratio.

Figure 11 shows a cross section of the low pressure column. It is possible to reduce the tray spacing below the 2.6 in used; however, data are not available for smaller tray spacing in air separation plants. Various packing materials (as in petrochemical separation processes) may be used in the column to reduce the height of a theoretical tray. Height equivalents to a theoretical tray of 1.5 to 2.5 in have been reported [12] but low temperature separation data are not available for these packings. Future generator development might consider the use of packed columns for an increase in the numbers of theoretical trays available in a fixed height.

\section{Heat Exchanger Design}

\section{1 Introduction}

The low temperature heat exchangers in the generator will be the plate-fin type which is used extensively in low temperature process plants. Such heat exchangers have the following advantages: 
a) More than two streams can be accommodated in the same exchanger.

b) Large amounts of surface area per unit length are available; therefore, the height of the exchangers will be less than for other types.

c) Total cross sectional area for plate-fin-type exchangers compares favorably with other types of exchangers.

d) Pressure drop can be controlled by the proper selection of plate spacing and fin dimensions.

Heat transfer correlations for the plate-fin-type exchangers are available from the various manufacturers. The correlations are based on a great amount of actual experience and are, therefore, quite reliable in predicting the performance of the exchanger. Computer programs are utilized by the manufacturers to arrive at exchanger size and configuration.

Heat exchangers for the compressor, blower after-coolers, and R-12 condenser are commercially-available units of the conventional forced-air finned-tube type. For shipboard operations these would be commercial shell and tube heat exchangers utilizing seawater for the cooling fluid. The R-12-gas heat exchanger is a commercially-available shell and tube heat exchanger.

\subsection{Heat Exchanger I}

The design of heat exchanger I of figure 1 is based on the process data indicated on the flow sheet. In order to permit manufacturers of the plate-fin-type heat exchangers to determine the size and configuration of the exchanger, a cooling curve of the exchanger 
was prepared as shown in figure 12. Properties of the gases used for the construction of the cooling curve have been taken from published thermodynamic properties of gases.

The cooling curve for heat exchanger I is typical of countercurrent flow low pressure gas-to-gas heat exchangers. Since the specific heat of the gas of the various streams is nearly constant, the cooling curves are essentially straight lines. The total duty for heat exchanger I is $6.29 \times 10^{5} \mathrm{Btu} / \mathrm{hr}$. Using the process conditions as given on the flow sheet and the cooling curve, a typical plate-fintype manufacturer's computer program has indicated that the size of heat exchanger I would be 12 in by 12 in core cross section by 90 in long. Headers are provided on each side of the ends to minimize total length.

\section{3 Heat Exchanger II}

The design of exchanger II of figure 1 is based on the process data shown on the flow sheet. The cooling curve for exchanger II is shown in figure 13. The cooling curve for exchanger II shows a severe pinch at the point where air at 78 psia pressure starts to liquefy (stream 12). This particular pinch point will determine the production level of the generator. As the pressure of the air to be liquefied is reduced below 78 psia, the temperature difference at the pinch point approaches zero. In reality the temperature difference will remain positive and the temperature difference at the warm end of the exchanger will increase. The net result is a los of refrigeration and reduced output of the generator. To insure that the pressure at the point of liquefaction is at its maximum, the pressure drop in stream 12 from the compressor through heat exchanger $I$ is kept at a minimum. 
Total duty for exchanger II is $5.01 \times 10^{4} \mathrm{Btu} / \mathrm{hr}$. From the cooling curve and process conditions, a typical manufacturer's computer program has indicated that the heat exchanger will have a cross section of 12 in by 12 in by 90 in long.

\section{4 Subcooler}

Subcooling the liquid nitrogen feed to the top of the low pressure column reduces flashing losses when expanding from 100 psia to 22 psia. Refrigeration for subcooling is supplied by the waste nitrogen from the low pressure column. In addition, the product liquid oxygen is subcooled to minimize flashing losses. Total duty of this heat exchanger

is $8.81 \times 10^{3} \mathrm{Btu} / \mathrm{hr}$. The manufacturer's computer program has indicated that the exchanger cross section will be 8 in by 6 in by 48 in long.

\subsection{Condenser-Reboiler}

The condenser-reboiler condenses the nitrogen from the top of the high pressure column to provide reflux liquid to both the high and low pressure columns. The liquid oxygen boils as the warmer nitrogen vapor is cooled and condensed. The oxygen vapor is then fed to the bottom of the low pressure column. Total duty for the condenser-reboiler is $1.07 \times 10^{5} \mathrm{Btu} / \mathrm{hr}$. The reboiler-condenser must be less than 28 in high to fit into the envelope and will have a core size of 12 in by 12 in.

\subsection{Compressor and Blower Aftercoolers}

Compressor and blower aftercoolers are commercial forcedair finned-tube heat exchangers. The main air compressor aftercooler duty is $7.92 \times 10^{5} \mathrm{Btu} / \mathrm{hr}$. Size of the unit, including fan and headers, will be $3 \mathrm{ft}$ by $5 \mathrm{ft}$ by $5 \mathrm{ft}$. The expander blower aftercooler 
duty is $4.56 \times 10^{4} \mathrm{Btu} / \mathrm{hr}$. This aftercooler consists of two units in parallel, each being $3 \mathrm{ft}$ in diameter by $1-1 / 2 \mathrm{ft}$ high.

\subsection{Refrigerant 12 Condenser and Air Cooler}

The R-12 condenser is a commercially available forced-air finned-tube heat exchanger. The unit selected consists of two equal size parallel units, each being 45 in by $42-1 / 2$ in by $39-3 / 8$ in.

The R-12 evaporator is a flooded shell and tube heat exchanger. Expected duty on this heat exchanger is $1.06 \times 10^{5} \mathrm{Btu} / \mathrm{hr}$. The exchanger is a 2 pass shell and tube heat exchanger, $12-3 / 4$ in in diameter and 108 in long.

\subsection{Defrost Heater}

A 20 kilowatt electric heater is provided to heat the defrost gas. The unit is a commercially available electric tubular element inline heater complete with temperature control. Size of the unit will be $8-5 / 8$ in in diameter by 60 in long.

\section{Machinery}

\section{I Introduction}

The liquid oxygen-nitrogen generator has a number of moving components. The number is larger than for the existing generator in order to make more efficient use of the refrigeration. The work done with regard to machinery consisted of contacting vendors of the required components. As stated in Section 10.5, the air compressor chosen for the generator is a unit which is very similar to the unit now used. The major difference from a standpoint of process design is the capability of circulating dry air free of impurities in a closed cycle. 
All other machinery is commercially available in standard units with a proven operating record. Advancements in the state of the art are not required.

\subsection{Expansion Engine and Blower}

A combination expansion engine and blower is available commercially to satisfy the process conditions shown in figure 1 . The expander is a rather standard unit of a size supplied and in operation since 1966. The blower uses all of the power available from the expander. Its efficiency is rather low due to the relatively small flow rate of air.

\subsection{Lobe-Type Blower}

Feed air to the generator is compressed to approximately 18 psia, sufficiently high to force the gas through the purification system into the suction of the main compressor. The blower is a commercially available unit which compresses air by the action of two figure eight-shaped impellers mounted on parallel shafts inside a casing rotating in opposite directions. A timing gear on each of the impeller shafts controls their relative position. The blower capacity is independent of the discharge pressure and the air is delivered free of oil. In order to eliminate the need for controls for the operation of the blower, a pressure controlled valve in the discharge line will return air to the atmosphere when the discharge pressure exceeds a certain level.

\subsection{Refrigerant 12 System}

The R-12 compressor with the evaporator and piping will form a closed system. All components of the system are commercially available and will be procured by specification. A deviation from using 
standard packaged equipment will only be made when it is necessary to fit the equipment into the envelope.

The size of the R-12 compressor chosen is dictated by the condition of stream 2 (figure 1). As mentioned in Section 7.2, the most severe condition chosen for the design of the generator is feed air of a $125^{\circ} \mathrm{F}$ temperature and a dew point of $90^{\circ} \mathrm{F}$.

The R-12 unit provides $120,000 \mathrm{Btu} / \mathrm{hr}$ of refrigeration at an evaporator temperature of $30^{\circ} \mathrm{F}$. The condenser operates in an environment of $125^{\circ} \mathrm{F}$ with a $20^{\circ} \mathrm{F}$ approach. (Refrigerant 12 condenses at $145^{\circ} \mathrm{F}$.)

\subsection{Air Compressor}

The existing generator employs a compressor which supplies air to the combustion chamber and drive turbine. In this study it has been assumed that a turbo compressor will be used, driven by an independent power turbine. With the power and compression systems separated, only the air fed to the columns must be purified.

\subsection{Liquid Oxygen Pump}

Either a reciprocating or centrifugal pump may be used to lift the 37.2 moles per hour of liquid oxygen from the bottom of the low pressure column to the reboiler-condenser some 8 feet higher. The actual volume pumped is only $17 \mathrm{cubic} \mathrm{ft} / \mathrm{hr}(8.15 \mathrm{cubic}$ in per sec) and is somewhat small for a centrifugal pump. Because of the limited liquid level in the sump the pump must operate with a very low NPSH (net positive suction head). A centrifugal pump with inducer capable of operating with a very low NPSH is commercially available. 
There are reciprocating liquid oxygen pumps on the commercial market but most of these are designed for very high dis charge pressures. Our low discharge pressure alleviates many of the design problems. A low speed pump, with rather large displacement and large inlet valve, is best suited when the NPSH is minimum.

\section{Insulation}

\subsection{Introduction}

Heat leak to the low temperature equipment reduces production capacity in any liquid oxygen generator but is especially damaging in smaller units. Selection of the proper insulation, therefore, becomes critical for the cold end of the generator. There are several types of insulation used extensively in low temperature separation plants. These include foams, gas-filled powders and fibers, evacuated powders and fibers, vacuum, and evacuated multilayer insulations. Choice of insulation is based on insulation effectiveness and such considerations as application, weight, and cost. Performance of the various insulations between ambient and the lowest temperature encountered in the air separation process are given in Table 11.1.

When space is limited, evacuated insulations offer the lowest heat flux. When properly designed and constructed, vacuum insulated containers have proven reliable and durable. When more space is available or when higher heat fluxes can be tolerated in parts of the process operating at higher temperature levels, gas-filled powders offer reasonable heat flux with simplified construction and low cost. 
Table 11.1

Performance of Various Insulation Systems

Type of Insulation

6 in polyurethane foam $\left(2 \mathrm{lb} / \mathrm{ft}^{3}\right)$

6 in perlite $\left(5-6 \mathrm{lb} / \mathrm{ft}^{3}\right.$ filled $\left.\mathrm{w} / \mathrm{N}_{2}\right)$

High vacuum $(\epsilon=0.02)$

6 in perlite - vacuum $\left(5-6 \mathrm{lb} / \mathrm{ft}^{3}\right)$

6 in vacuum-multilayer insulation
Heat Flux $\mathrm{Btu} / \mathrm{Hr} \mathrm{Ft}^{2}$

15.3

15.2

2.84

0.50

0.01

\subsection{Column Cold Box}

Figure 14 shows a proposed arrangement of the cold box in which the lowest temperature components of the generator (i.e., columns, subcoolers, liquid oxygen pump) are housed. The cold box consists of a lower vacuum insulated container with a load bearing flat plate bottom. This container is 60 in O.D. by 42 in high. An omega bellows in the outer wall compensates for the thermal contraction of the inner wall and maintains the load bearing capability of the bottom. The upper vacuum-jacketed cylindrical container is 44 in O.D. by 82 in high. Again, an omega bellows in the outer wall provides for thermal contraction. The inverted cylinder upper vessel is located off center from the lower cylinder and is supported by the flat nonvacuum-jacketed cover of the lower container. To prevent excessive heat transfer between the nonvacuum-jacketed cover plate and the cold bottom of the lower container, the upper vacuum jacket extends some $2 \mathrm{ft}$ below the plate. With this arrangement both upper and lower containers are readily removed for access to the cold equipment. 
None of the components located inside the vacuum insulated jacket need to be vacuum tight since a waste gas atmosphere of 1 atmosphere is maintained inside the box. In case of problems with the vacuum insulation, either the upper or lower container may be quickly replaced.

In order to prevent heat transfer by convection currents, all components and piping inside the cold box are wrapped with fiberglass blankets. The total heat leak to the cold components is estimated to be approximately $500 \mathrm{Btu} / \mathrm{hr}$.

\subsection{Heat Exchanger Cold Box}

Insulation for heat exchangers I and II will be gas-filled powder. The relatively high heat leak of gas-filled powder will not affect the performance of the generator greatly, since this heat is directly removed by the return cold gas stream from the expansion engine.

The heat exchanger cold box will be made of structural support members with sheet metal sides. Provisions will be made to add to or remove the powder insulation. A nitrogen purge will be supplied from the waste nitrogen stream to prevent moisture from entering the insulation.

\subsection{Insulation of Purification System}

Insulation is required for the R-12-air cooler and purification system. The operating temperature of the R-12 unit is $30^{\circ} \mathrm{F}$ and pre-formed foam insulation will be used. The drier and carbon dioxide removal unit, however, will experience temperatures of the order of $500^{\circ} \mathrm{F}$ during reactivation of the adsorbent bed. Commercially 
available magnesium oxide will be used to insulate the adsorbers for both high and low temperatures.

\section{Physical Arrangement}

\subsection{Introduction}

The space available for all of the equipment is $8 \mathrm{ft}$ by $8.5 \mathrm{ft}$ by $15 \mathrm{ft}$. All equipment, with the exception of the components in the column cold box, are commercially available components. No attempt was made to optimize the packing arrangement of these components through rearrangement of piping, instruments, etc. Rough scale models in the form of cubes, square boxes, and cylinders were used to fit the equipment in the allotted space.

It appears that the space available is sufficient to accommodate the 4 tons per day generator equipment when the feed air has a maximum dew point of $90^{\circ} \mathrm{F}$ and a temperature of $125^{\circ} \mathrm{F}$. A dew point of $125^{\circ} \mathrm{F}$ requires a bulkier $\mathrm{R}-12$ system and it is not clear that the larger R-12 system can be accommodated. Packaging into a minimum volume of all the components with piping, instrumentation, access for maintenance, etc. is a major job and outside the scope of this study.

\subsection{Column Cold Box Arrangement}

Figure 15 shows the proposed cold box plan view and partial elevation. The plate between the upper and lower vacuum-insulated cylinders will be supported from the structure of the generator envelope. All penetrations into the cold box pass through the support plate, i.e., all valves, transfer lines to the other cold box and for products, and the liquid oxygen pump. 
Figures 16 and 17 show the plan and elevation view of the equipment inside the cold box. An equipment support plate is structurally connected to the main support plate between the two vacuum-insulated cylinders. The columns and heat exchangers will be equipped with bumpers at the top of the box to insure stability in the horizontal plane.

\subsection{Equipment Arrangement}

Figures 18 and 19 are the plan view and elevation view of all the generator equipment in the envelope. The figures show that the space occupied by the air separation equipment (heat exchangers, expander-blower, and columns) occupies only 30 percent of the total space.

The air compressor with its aftercooler and associated equipment occupies the same space as the existing portable generator. The purification unit ( $R-12$ compressor, condenser, air cooler, drier, and $\mathrm{CO}_{2}$ adsorbers) occupies 20 percent of the total space. There is sufficient space for instrumentation and a control panel located on one side of the generator. The remaining space would be utilized for piping and valves. A complete and detailed design of the generator unit, including enclosure, supports, piping, and valves, may result in some revision of the equipment; however, sufficient space is available for the required equipment to satisfy the 4 tons per day design conditions.

\subsection{Instrumentation and Controls}

Instrumentation and controls for the generator are commercially available types for temperature, pressure, liquid level, and flow. Control functions utilize commercial pneumatic controllers. Air for 
operation of the pneumatic controllers is supplied from the main air compressor with high pressure gas cylinders for startup. For machinery operation and protection, electric controls are provided as required. Electric power is supplied from the generator unit operating from the main air compressor driver.

Once the plant is in normal operation, the automatic controls maintain the proper process parameters. Failure of any process equipment or controller automatically shuts the generator down in a safe condition and indicates on a master alarm panel the cause of the shutdown. After corrective action is taken, the plant is manually placed back in operation and the unit returned to automatic operation.

\subsection{Power and Weight}

The following tables list the weight and power requirements of the required equipment.

Table 12.1

Equipment Weight

Description

1. Air Compressor Package (Includes Driver and Electrical)

2. Air Compressor Aftercooler

3. Lobe Blower

4. $\mathrm{H}_{2} \mathrm{O}$ Knockout Drum

5. Drier and $\mathrm{CO}_{2}$ Adsorber

6. R-12 Compressor Package

7. R-12 Condenser

8. R-12 Air Cooler

9. Column Cold Box
Weight-Lb.

1,000

2,500

720

50

2,600

1,060

1,100

1,350

1,000 
Table 12.1 (Continued)

Description

10. High and Low Pressure Columns

11. Subcooler

12. Condenser-Reboiler

13. Liquid Oxygen Pump

14. Heat Exchangers I and II

15. Blower Expander

16. Blower Aftercooler

17. Piping, Valves, and Instrumentation

18. Electric Heater TOTAL
Weight-Lb.

$\begin{array}{r}300 \\ 60 \\ 60 \\ 50 \\ 700 \\ 100 \\ 332 \\ 800 \\ 195 \\ \hline\end{array}$

13, $977 \mathrm{Lb}$.

Table 12.2

\section{Power Requirements}

Description

1. Air Compressor (Lube System and Starter Motor)

2. Air Compressor Aftercooler

3. Lobe Compressor

4. R-12 Compressor

5. R-12 Condensers

6. Blower-Expander Lube System

7. Blower Aftercooler

8. Liquid Oxygen Pump

9. Electric Heater

10. Instrumentation and Controls

11. Lighting
Power-H.P.

10.00

30.00

1.50

0.25

1.00

0.10

27.00

2. 00

2.00 TOTAL ................. $90.85 \mathrm{H} . \mathrm{P}$. 
From the Equipment Weight Table, 12.1, it can be seen that the weight of the purification equipment is $6,8801 \mathrm{~b}$ or 49 percent of the total equipment weight. The weight of the air compressor package and air separation equipment is $6,102 \mathrm{lb}$ or 43.5 percent of the total weight. The effect of adding the high temperature level R-12 refrigeration equipment with the warm moisture and $\mathrm{CO}_{2}$ adsorbers is to essentially double the weight of the generator.

\section{Conclusions and Recommendations}

The following conclusions may be drawn from this study:

1. A capacity of approximately 4 tons per day of liquid oxygen or liquid nitrogen appears feasible within an envelope of $8 \mathrm{ft}$ by $8.5 \mathrm{ft}$ by $15 \mathrm{ft}$, with a maximum weight of $15,000 \mathrm{lb}$, and with an existing air compressor package. The main features of the generator are:

a) A closed cycle R-12 refrigeration system cools the feed air to the generator to approximately $40^{\circ} \mathrm{F}$ and condenses most of the water in the feed air.

b) A purification system consisting of two desiccant beds filled with molecular sieve, Type $13 \mathrm{X}$, removes all of the remaining water vapor and carbon dioxide at a temperature of $35-45^{\circ} \mathrm{F}$.

c) The expansion engine generates the power to compress some of the feed air to a pressure of 105 psia. This makes it possible to operate a more or less standard double column with reboiler-condenser, improves the utilization of available refrigeration, and increases the fraction of oxygen separated from the feed air. 
d) Height limitations of the generator makes it necessary to use a small liquid oxygen pump.

e) Using vacuum insulation reduces heat leak to the distillation columns and reboiler-condenser to a minimum.

2. The increase in production capacity using the same pressure and compressor flowrate is due primarily to the addition of the R-12 unit, i.e., large amounts of high temperature refrigeration. The process is thermodynamically more efficient at the expense of greater complexity. Many times, thermodynamic efficiency is a poor criterion by which to judge cryogenic equipment intended for field use. If a higher capacity air compressor could be used, then some of the expander refrigeration capacity could be employed to chill the feed air for water removal. The process would be thermodynamically less efficient but would be simpler and probably more reliable and easier to maintain.

3. Within the allowable height of $8.5 \mathrm{ft}$, the columns must be placed side by side. The low pressure column design and operation are critical. The reflux ratios are fixed and the number of trays which can be installed within the $8.5 \mathrm{ft}$ height is barely enough to produce liquid oxygen of the specified purity. If, for some reason, the number of trays proves to be insufficient, the required purity of the liquid oxygen can be obtained by either drastically reducing the output of the generator or using packed columns. 
4. The water content of the feed air to the generator is very important. A high water content adds weight and bulk to the generator through increased requirements for the purification system. It might be advantageous to plan for a separate package consisting of an $\mathrm{R}-12$ refrigeration system and water knockout drum for localities of extremely high humidity and air temperature and to design the basic generator for operation in more moderate climates.

5. To obtain reliability and simplicity of operation, the portable liquid oxygen generator should not be optimized in terms of production rate relative to input power. 


\section{References}

1. ASTM metric practice guide, Nat. Bur. Stand. (U.S.) Handb. 102 , (March, 1967).

2. Navair 19075 AAC-8, Operation, service, and repair instructions with illustrated parts breakdown; Liquid oxygen/nitrogen generating plant Model GB-1A (June 1967).

3. Brown, Ross, M., A portable liquid oxygen plant employing a low pressure cycle, Paper No. 51 a, AICHE National Meeting 61 st, Houston, Texas, Feb. 19-23, 1967.

4. Arnett, R. W. , and Muhlenhaupt, R。 C., Study of oxygen and nitrogen generating systems, Unpublished NBS Report (Sept. 1970).

5. Barron, Randall, Cryogenic Systems (McGraw Hill, 1966).

6. Ruheman, M. , The Separation of Gases (Oxford University Press, 1949).

7. Claitor, L. C., and Crawford, D. B., Thermodynamic properties of oxygen, nitrogen and air at low temperatures, Trans. ASME 71, 885 (1949)。

8. Cryogenic Consultants, Inc., Proprietory information.

9. Linde Report, AIChE meeting, Sept., 1956.

10. Cryogenic Consultants, Inc., Proprietory information.

11. Latimer, R. E。, Private communication, 1958.

12. Perry, J. H., Chemical Engineer's Handbook, 4th edition (McGraw Hill, 1963).

13. Manufacturer's computer program for heat exchanger design.

14. Flow of fluids through valves, fittings, and pipe, Crane Tech. Paper No. 410 (1942). 
15. Barron, Randall, Cryogenic Systems, p. 497 (McGraw Hill, 1966).

16. Crawford, D. B., Elliot oxygen process and impurity removal system, Chemical Eng. Progress $\underline{46}$, No. 2 (1950).

17. McCabe, W. L., and Thiele, E. W., Ind。 Eng. Chem。17, 605 (1925).

18. Latimer, R. E. , Private communication, 1958. 

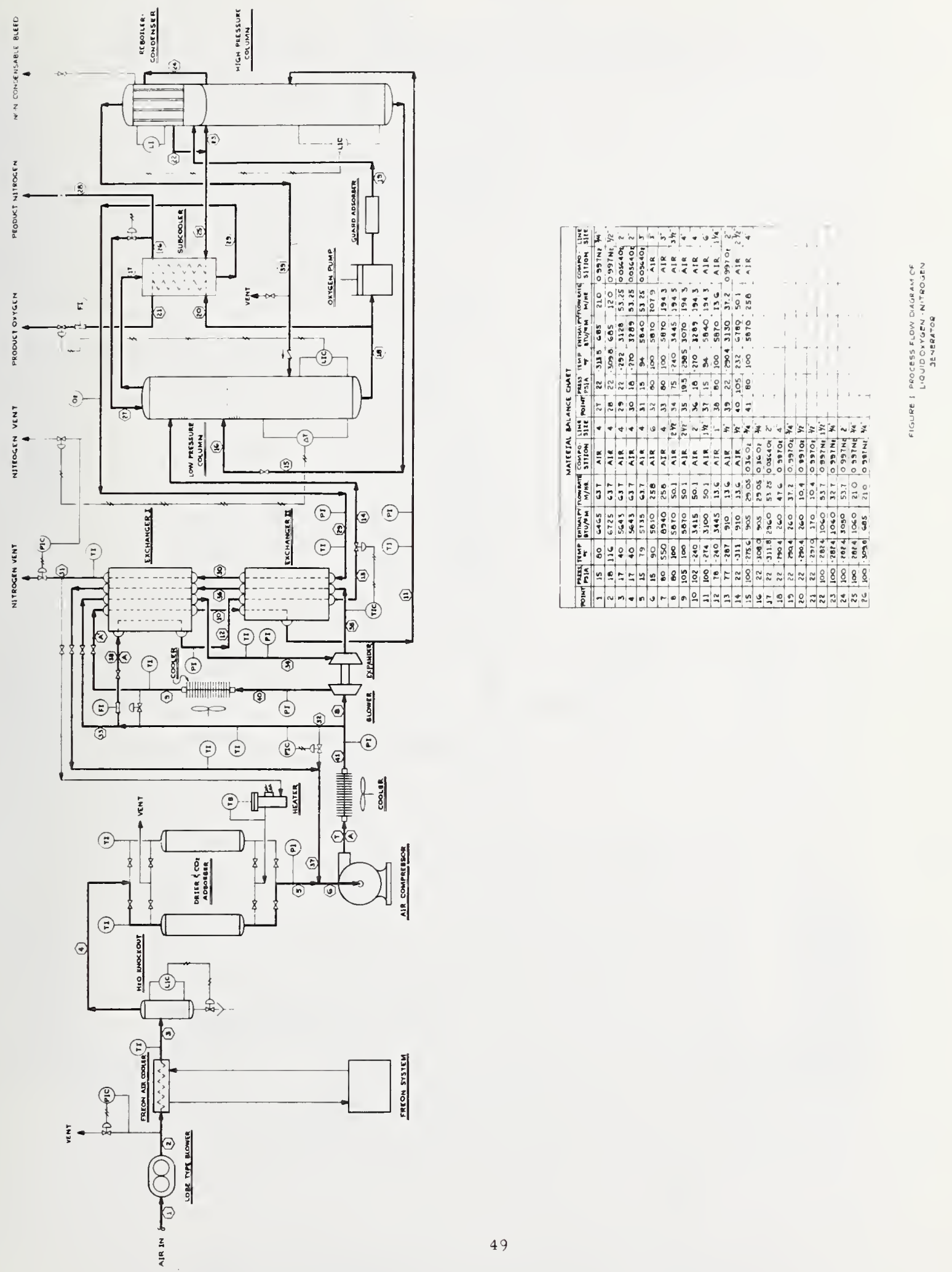
STREAM 3
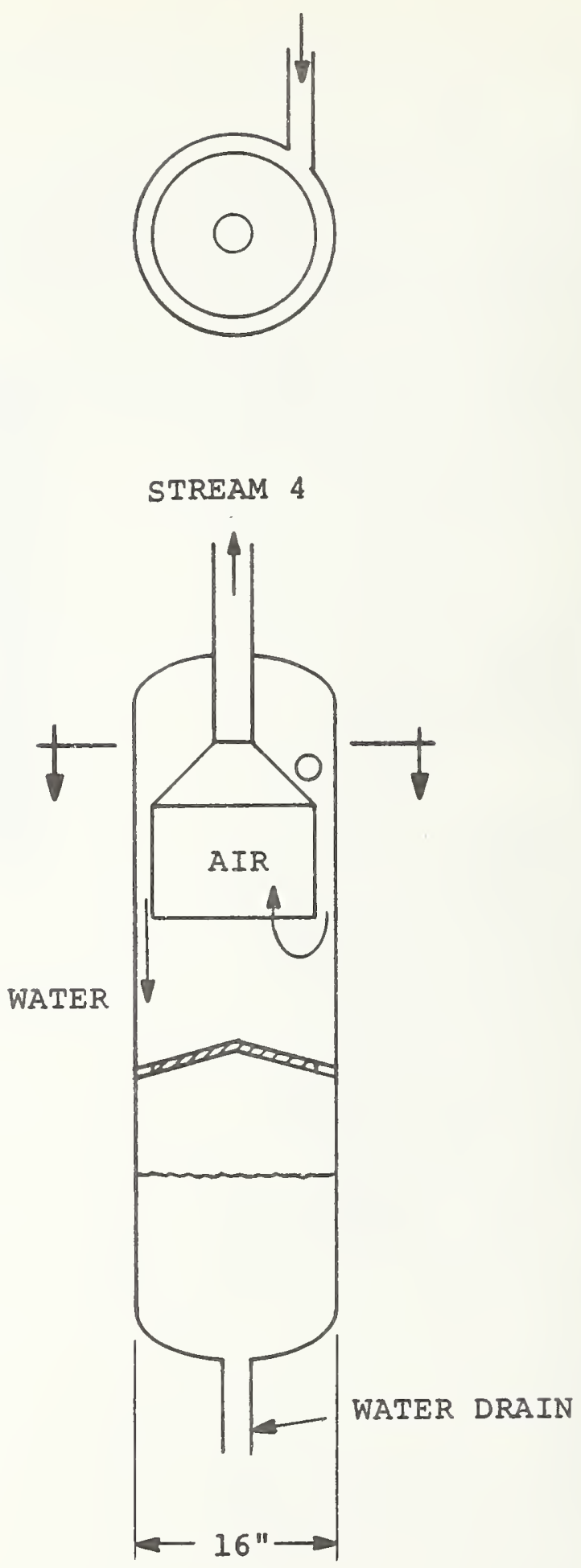

FIGURE 2. GENERAL ARRANGEMENT OF THE WATER KNOCKOUT DRUM 


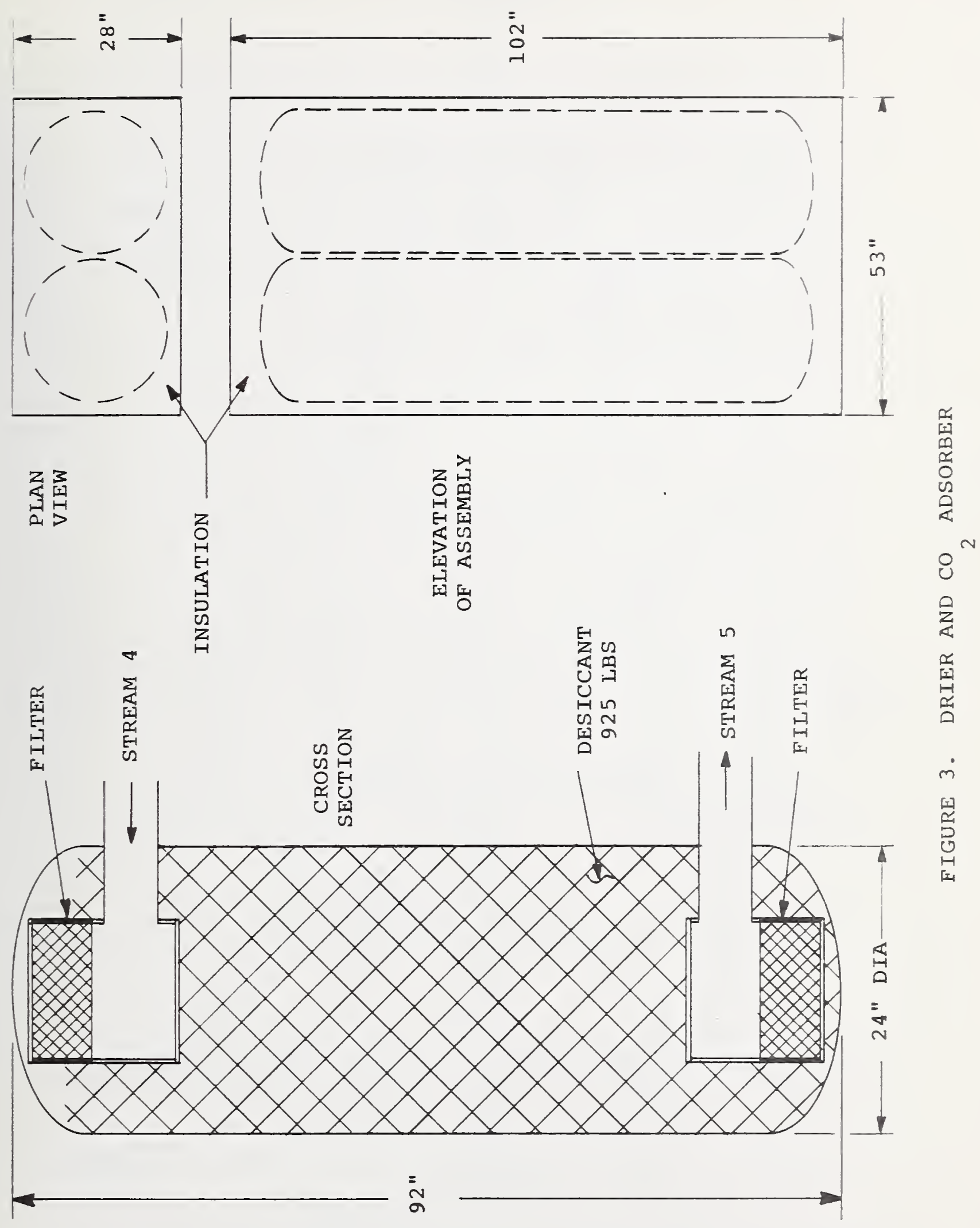




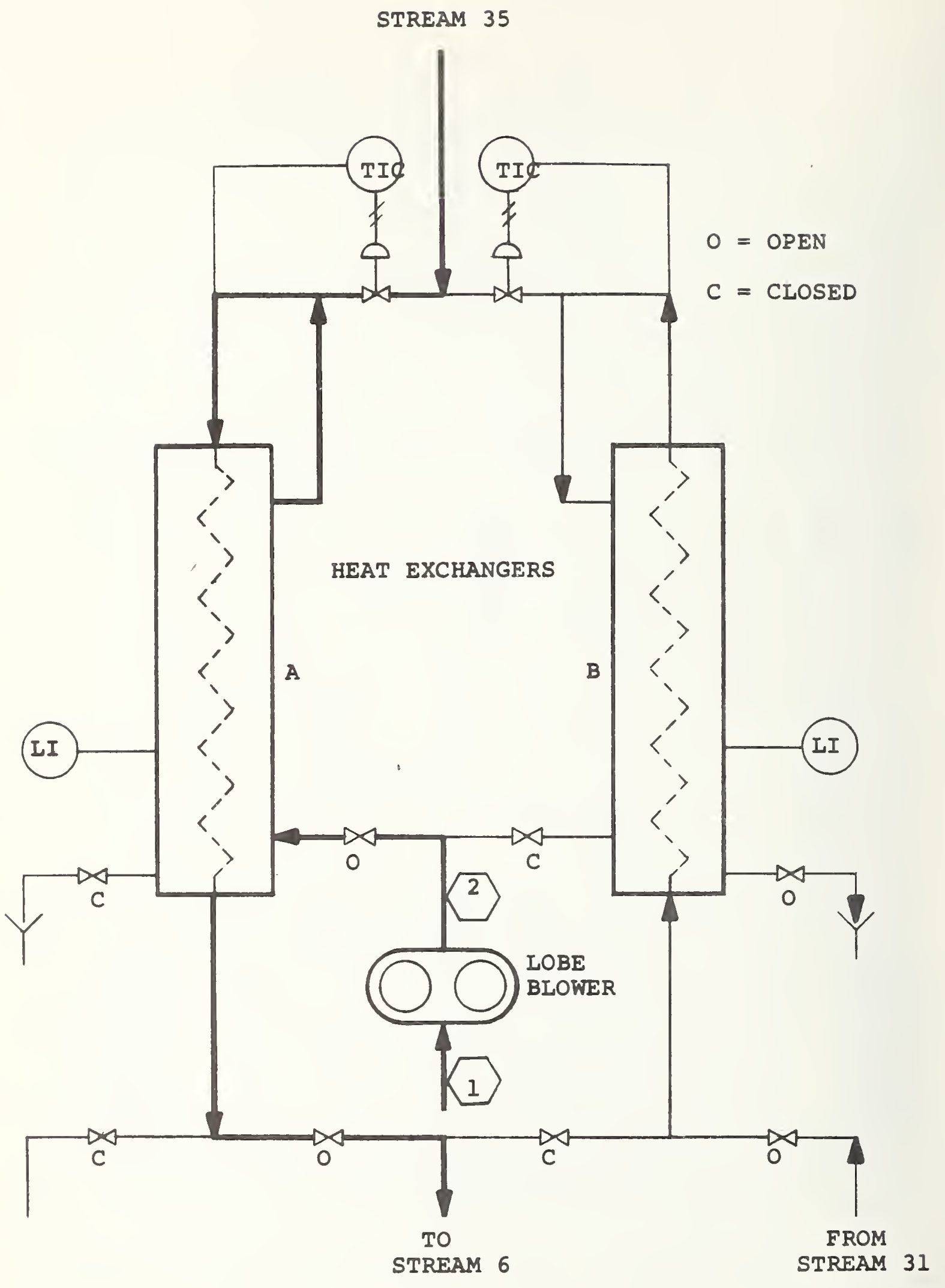

FIGURE 4. IMPURITY REMOVAL THROUGH IIQUEFACTION AND SOLIDIFICATION 


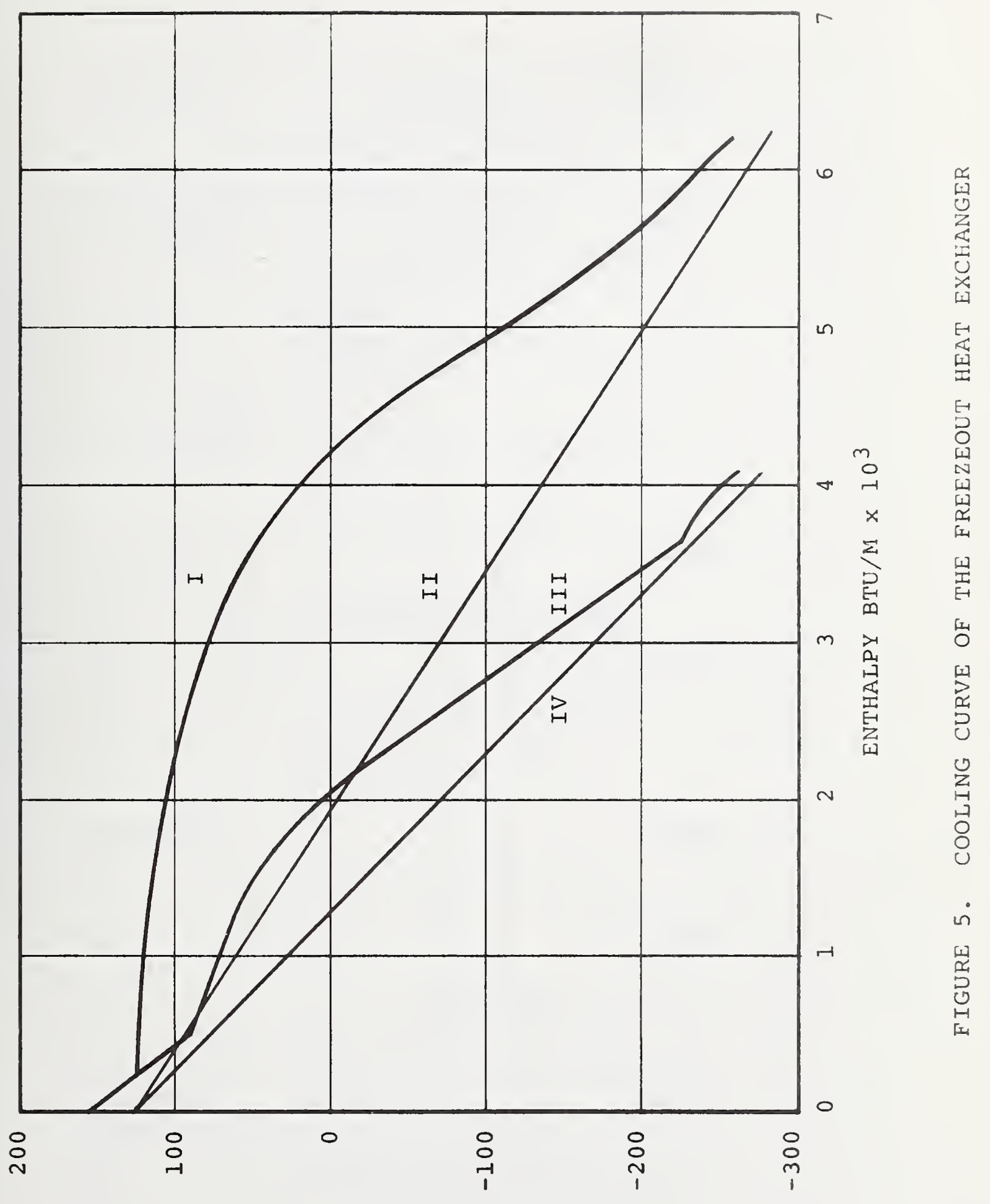

TEMPERATURE ${ } F$ 


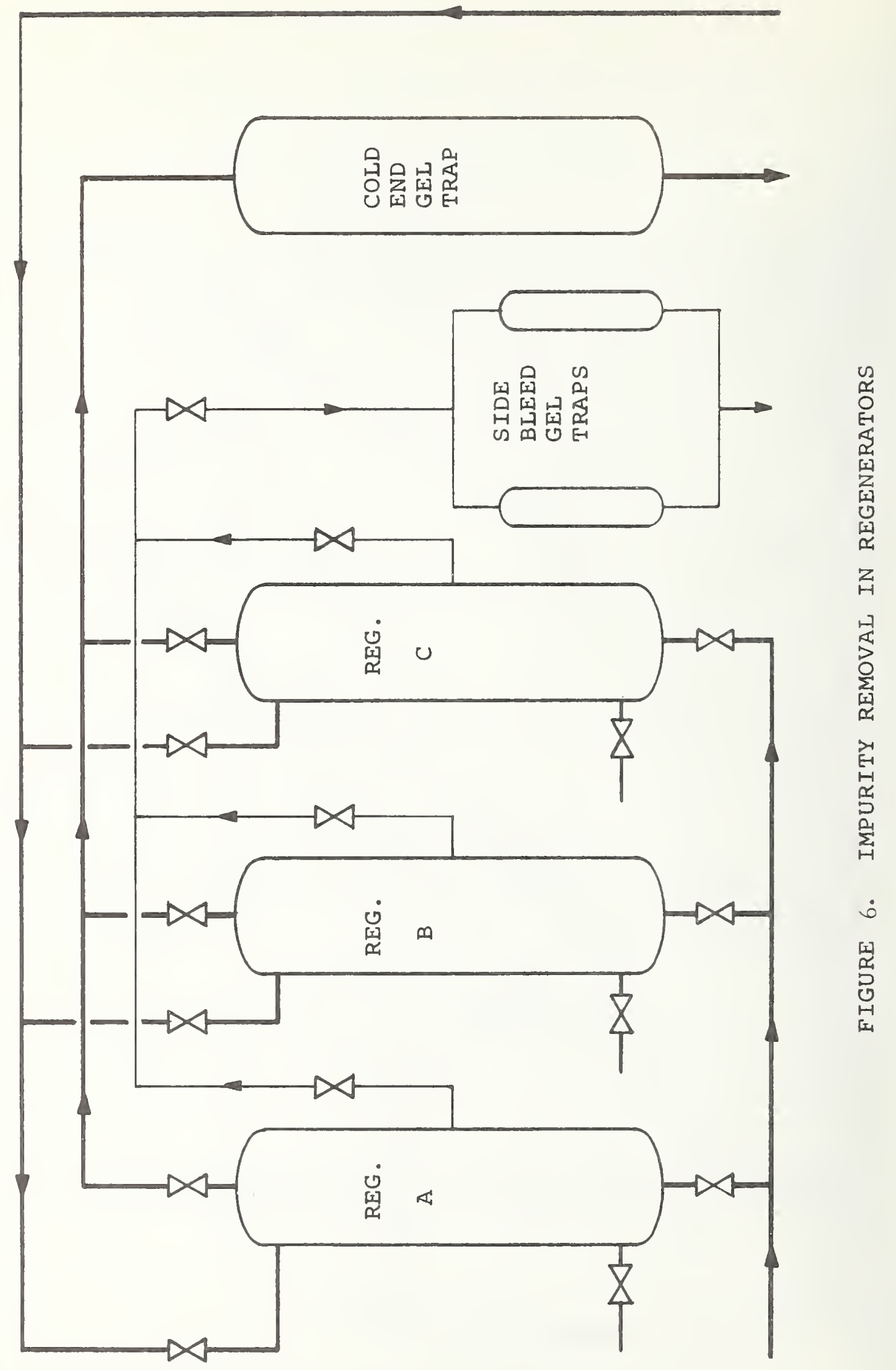




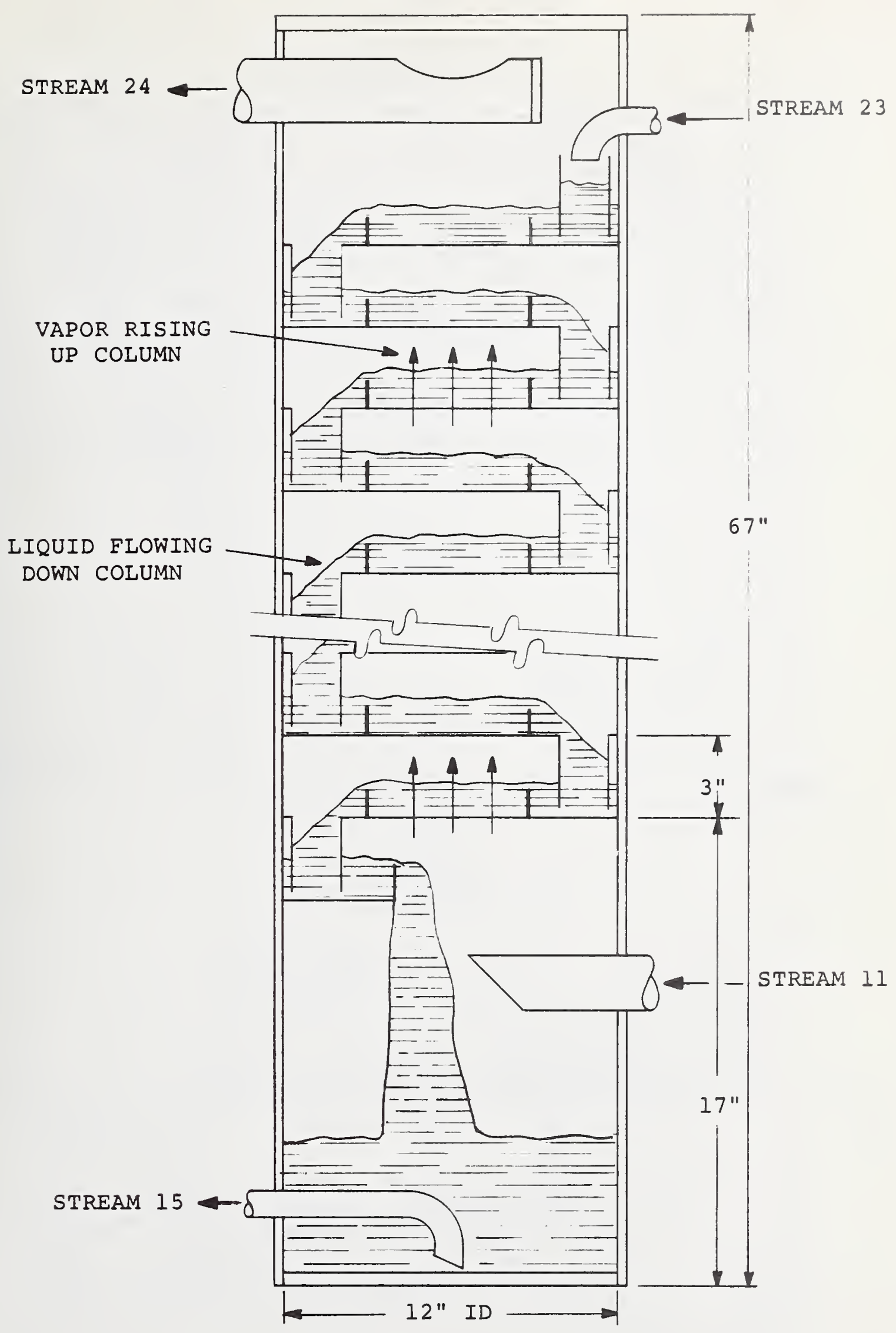

FIGURE 7. HIGH PRESSURE COLUMN CROSS SECTION 


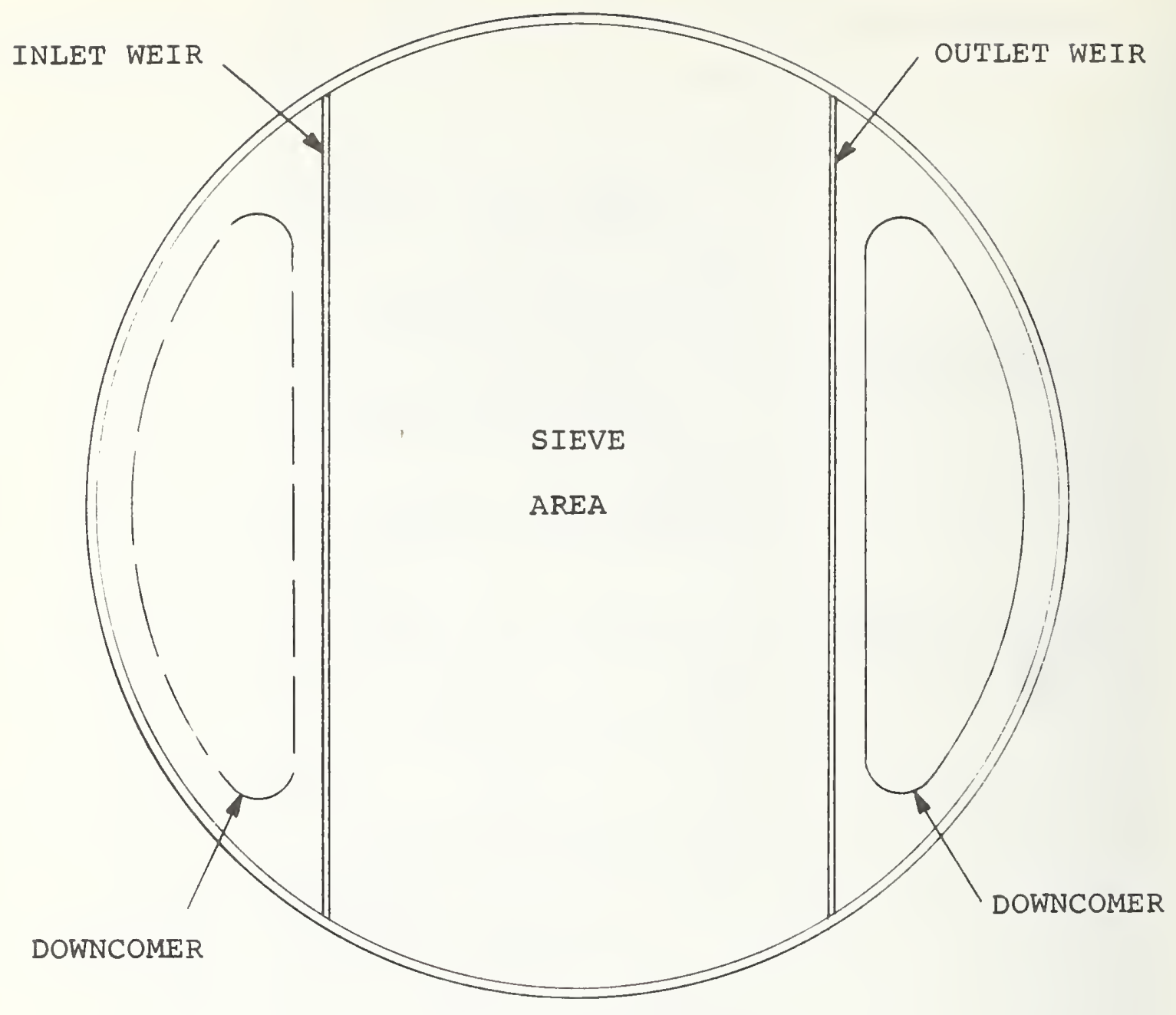

PIAN VIEW

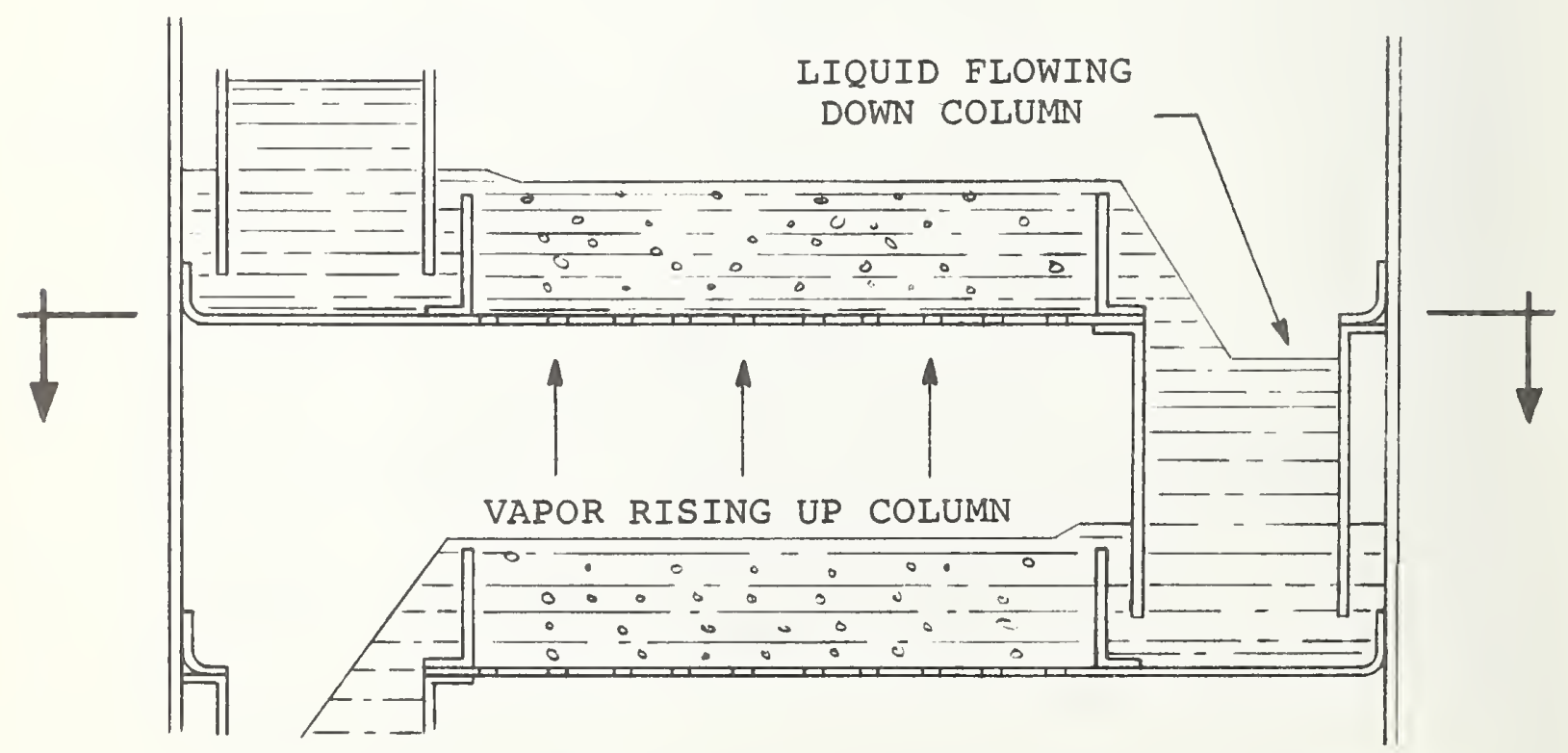

FIGURE 8. COLUMN CROSS SECTION TYPICAL TRAY 


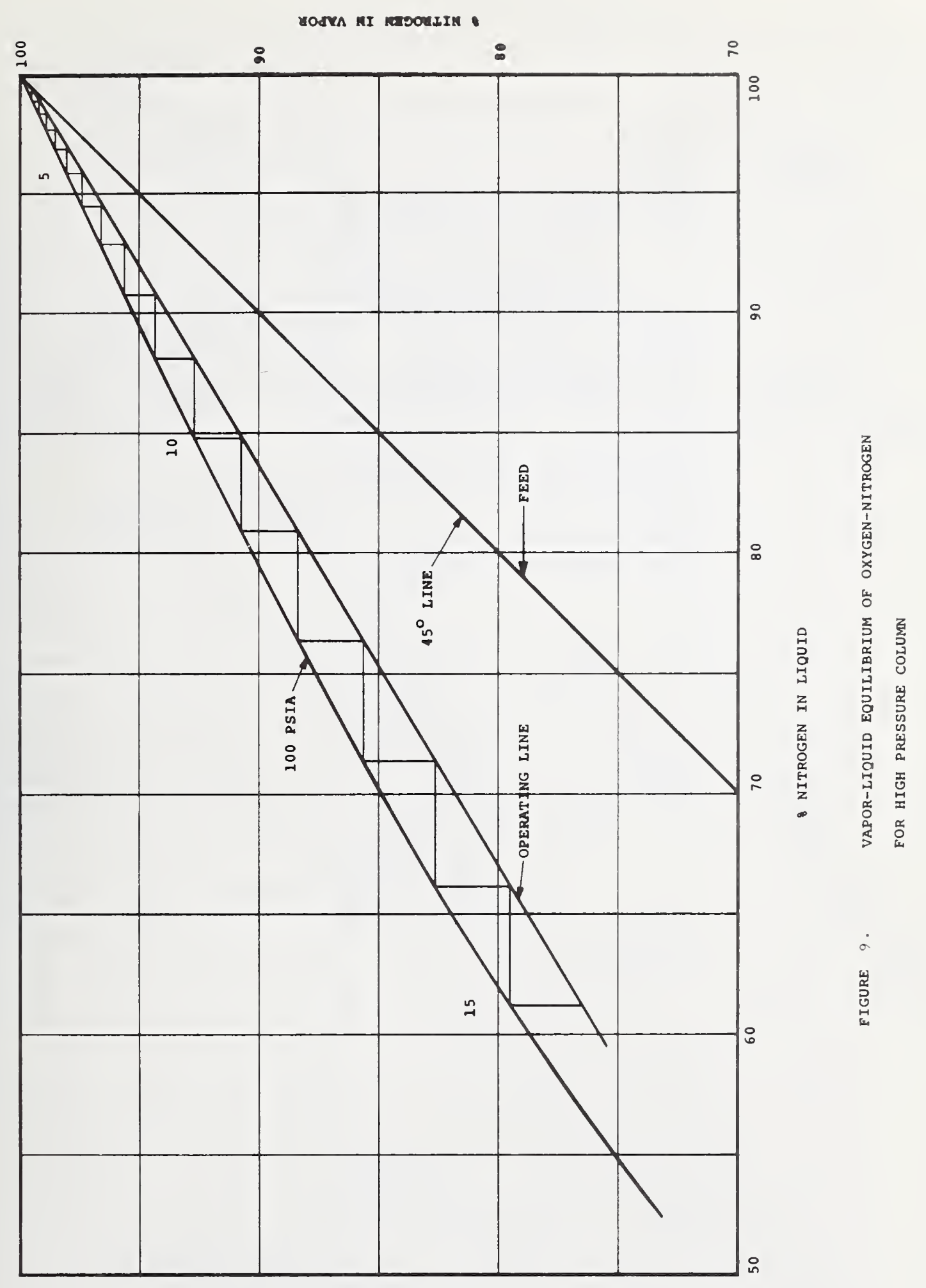




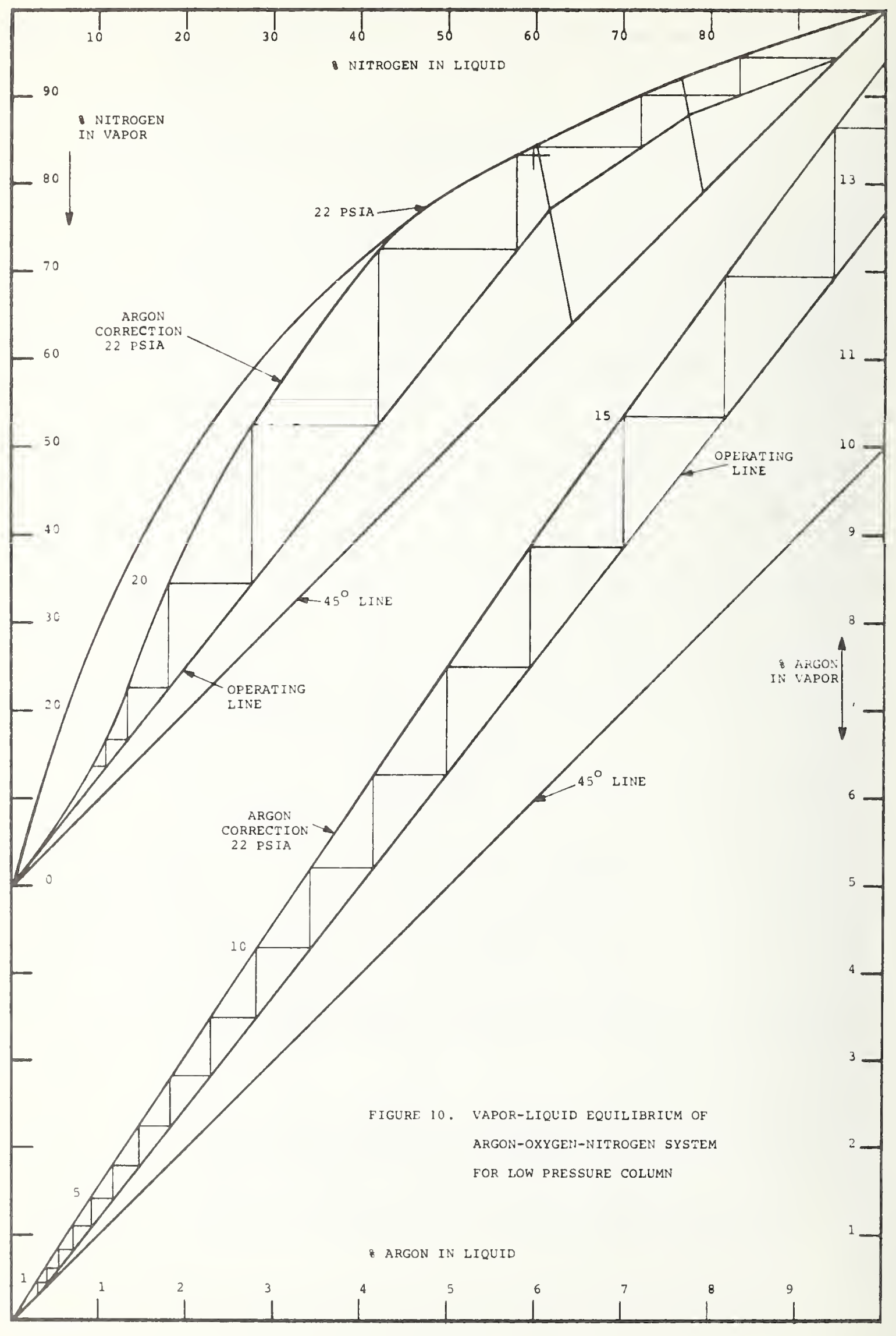




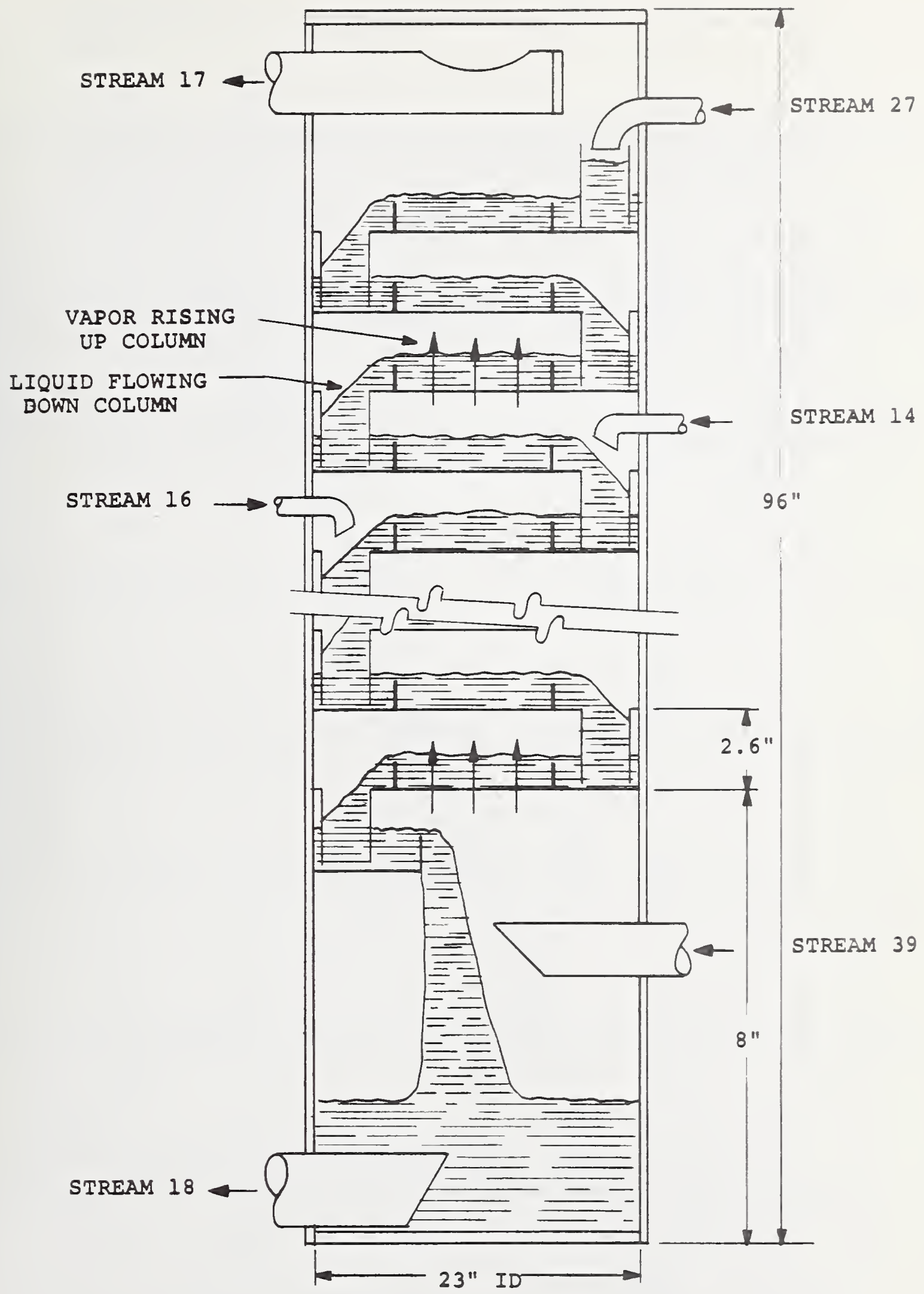

FIGURE 11. LOW PRESSURE COLUMN CROSS SECTION 


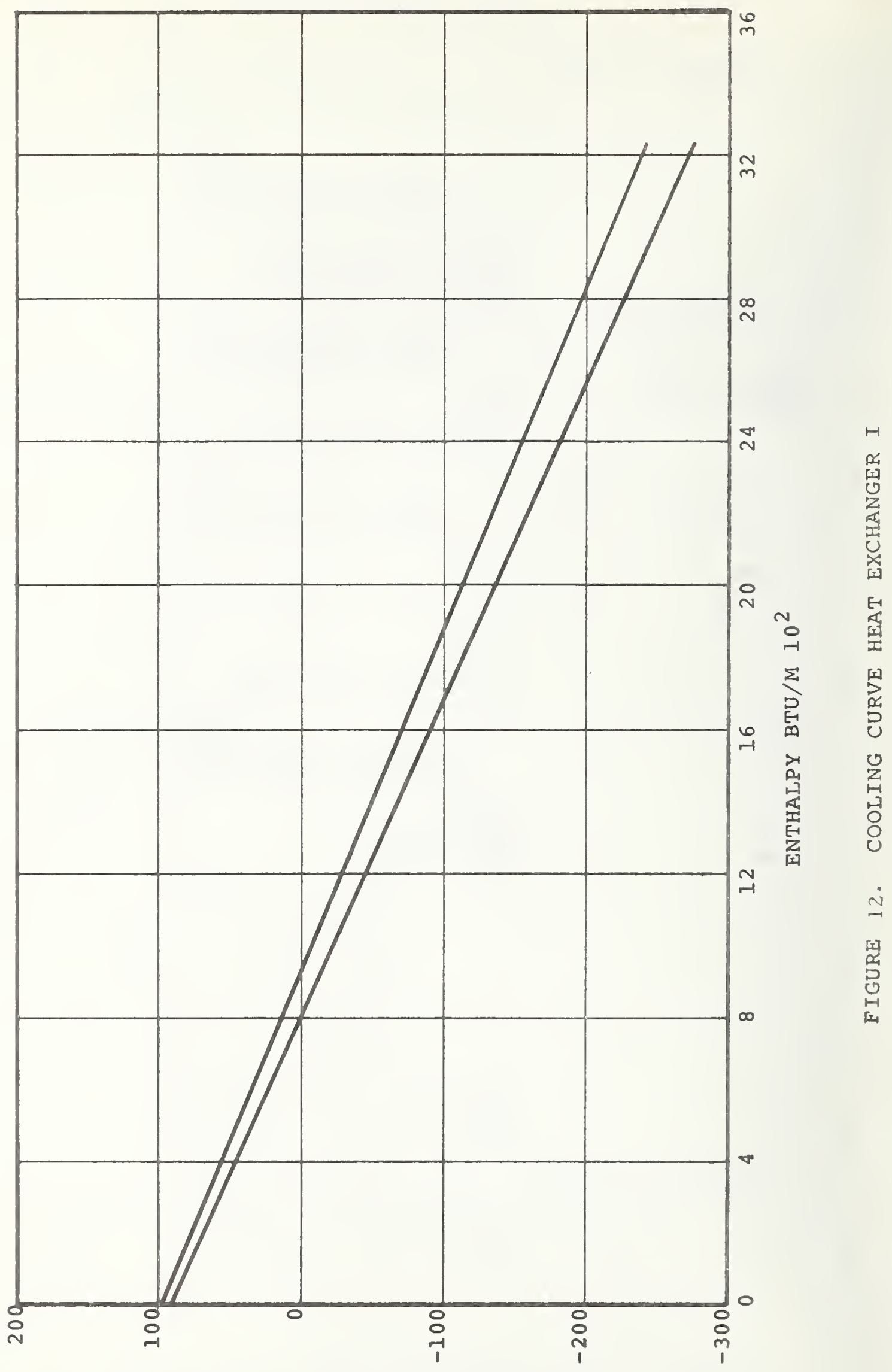

TEMPERATURE OF 


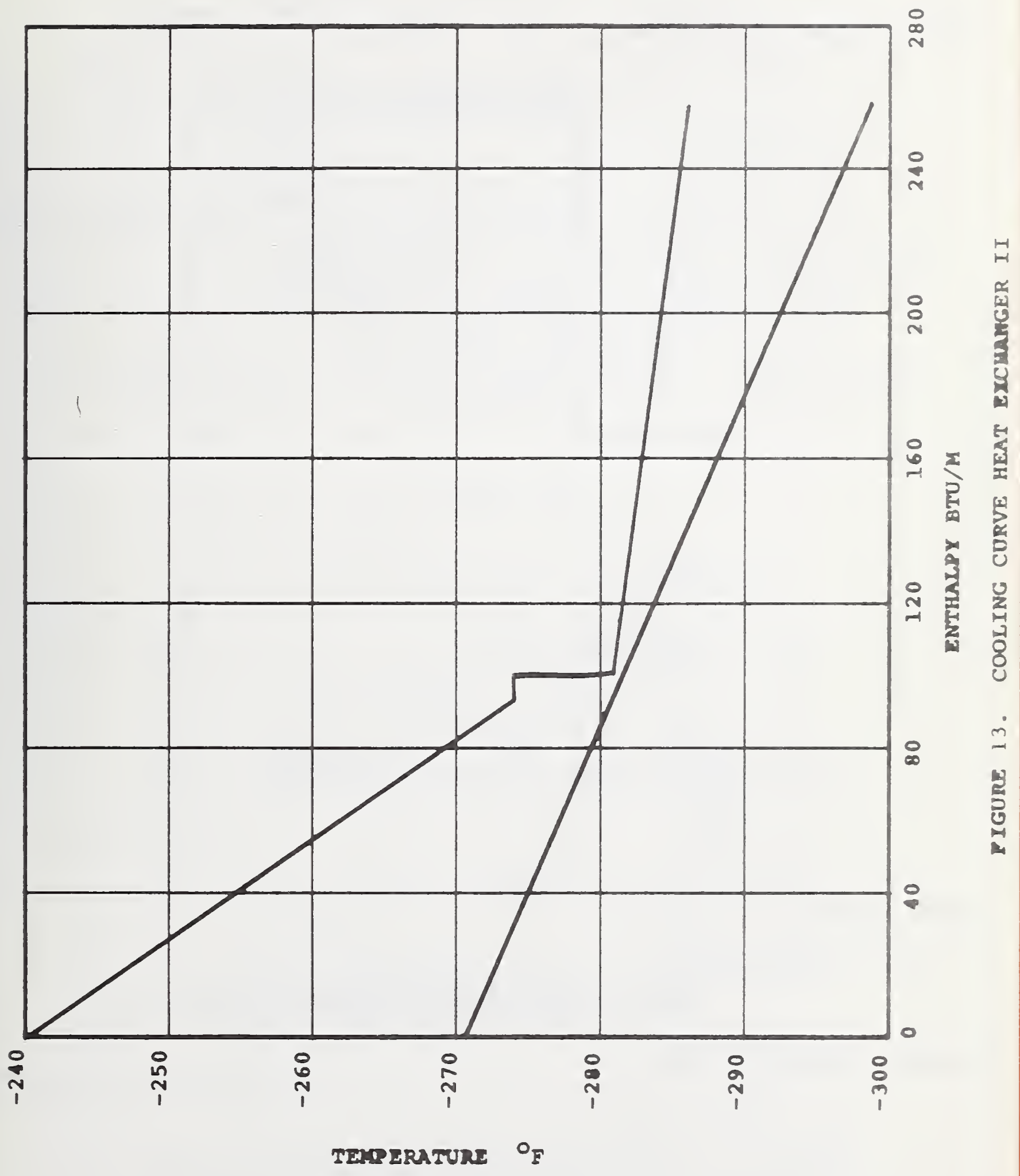




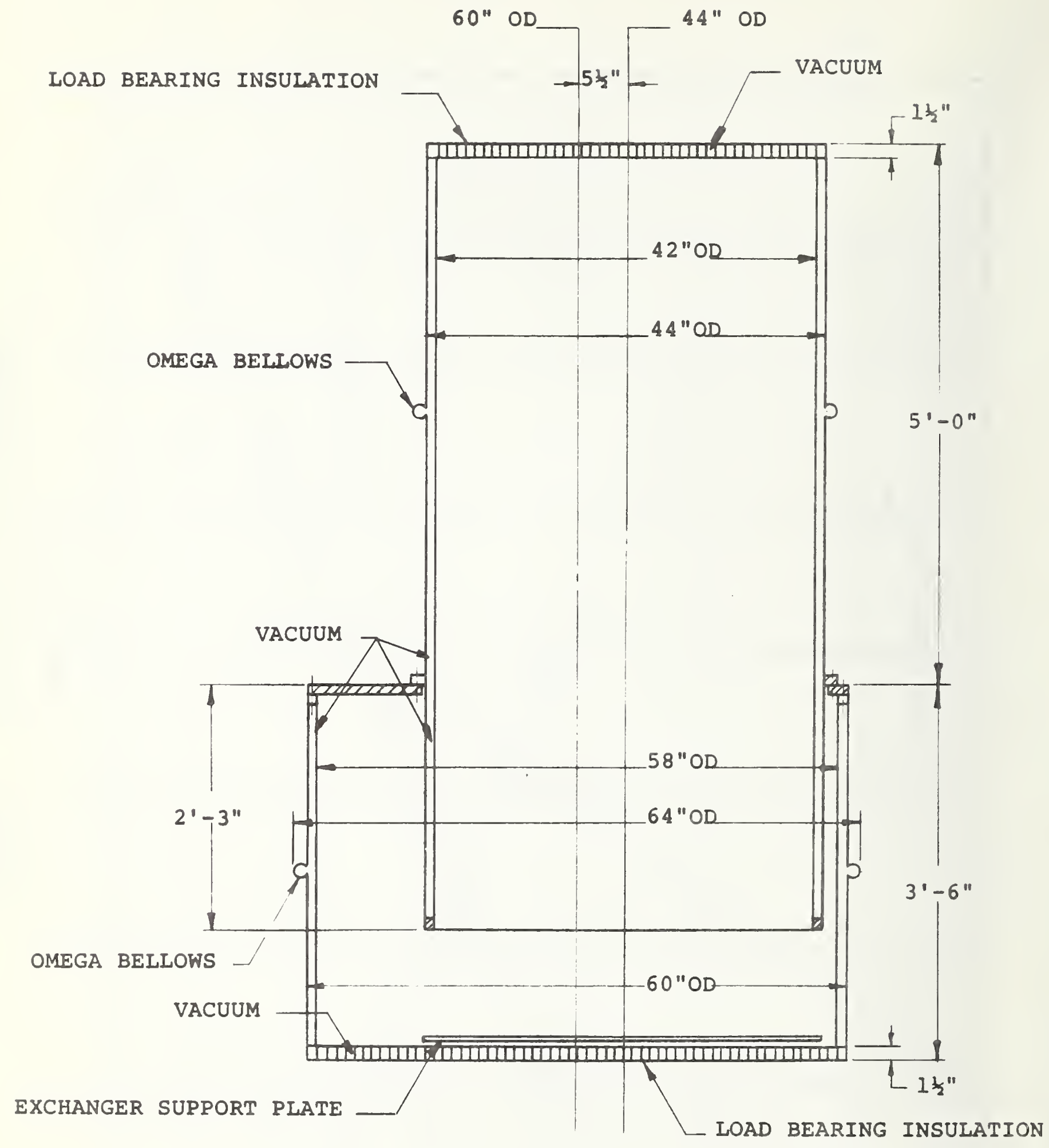

FIGURE 14. VACUUM INSULATION FOR COLUMN COLD BOX 


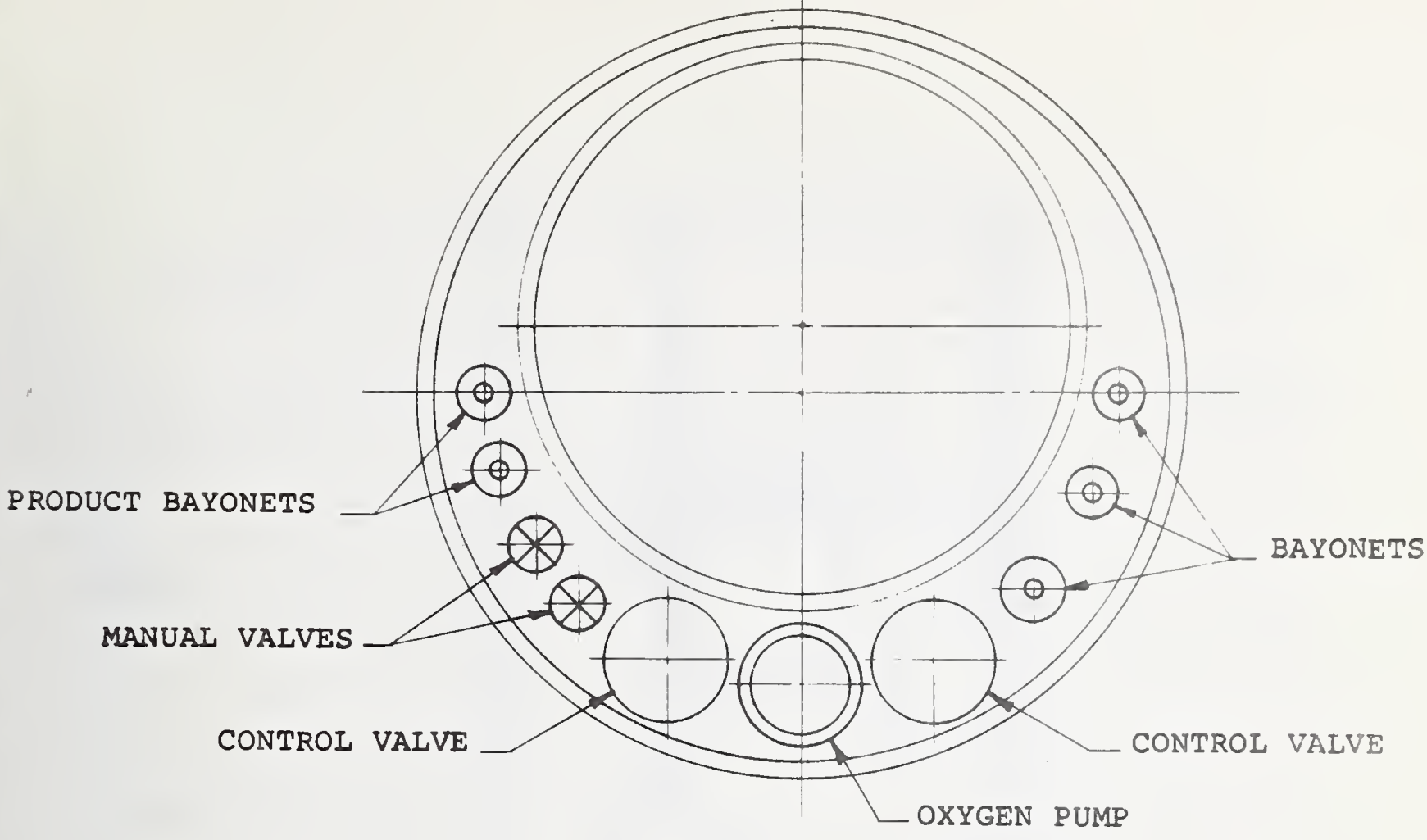

PLAN VIEW

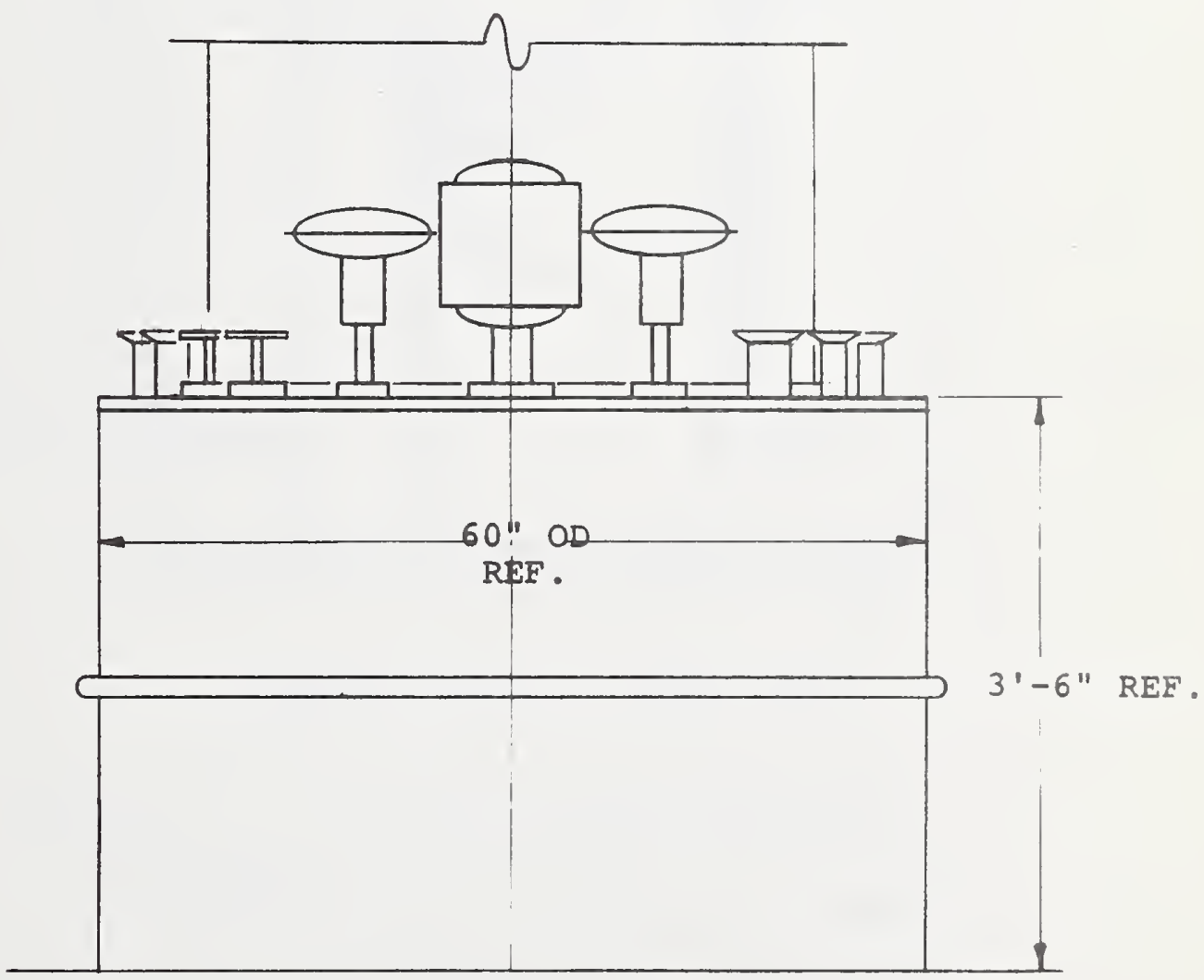

FIGURE 15. COLUMN COLD BOX PARTIAL ELEVATION 


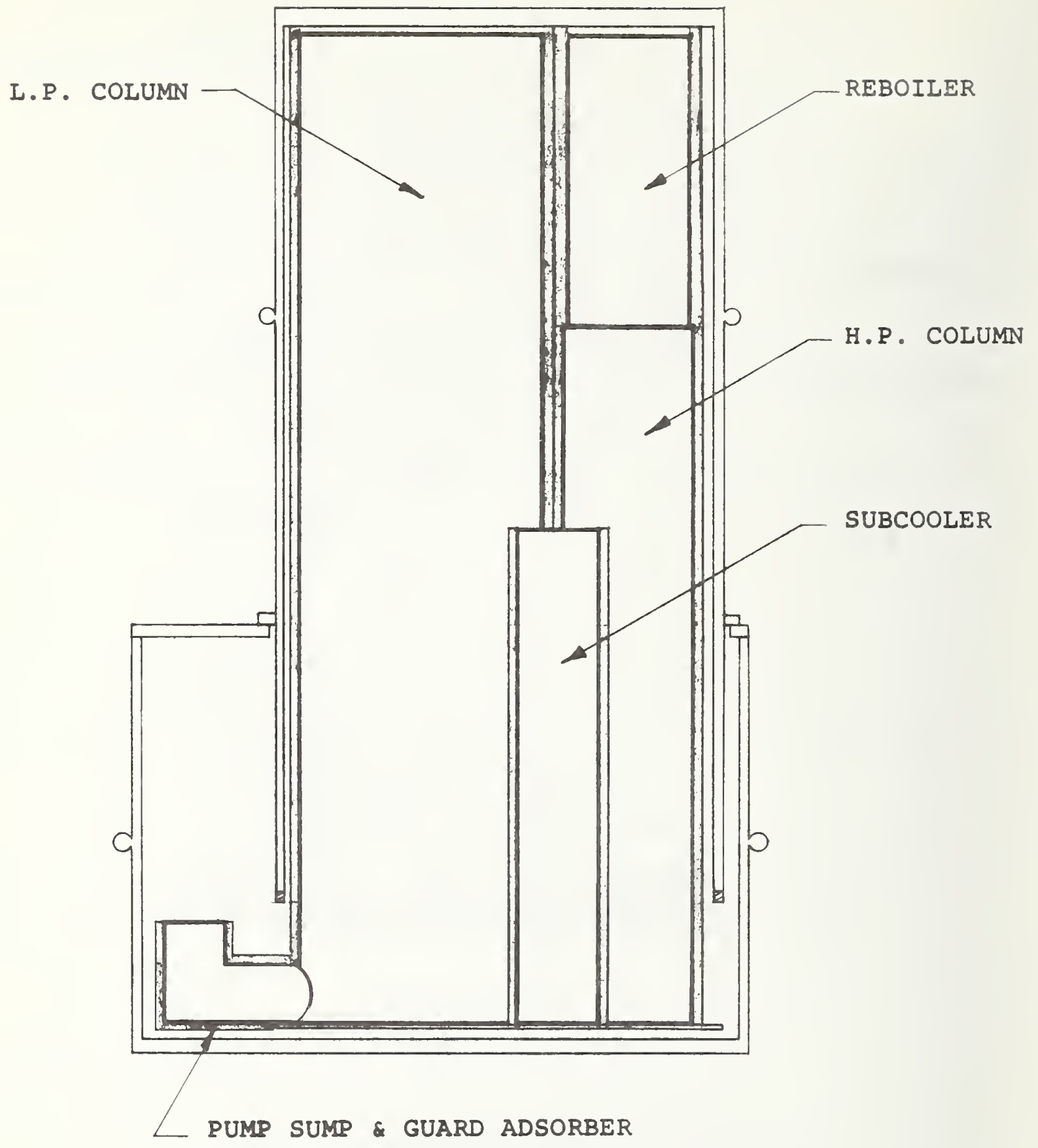

FIGURE 16. COLUMN COLD BOX ELEVATION 


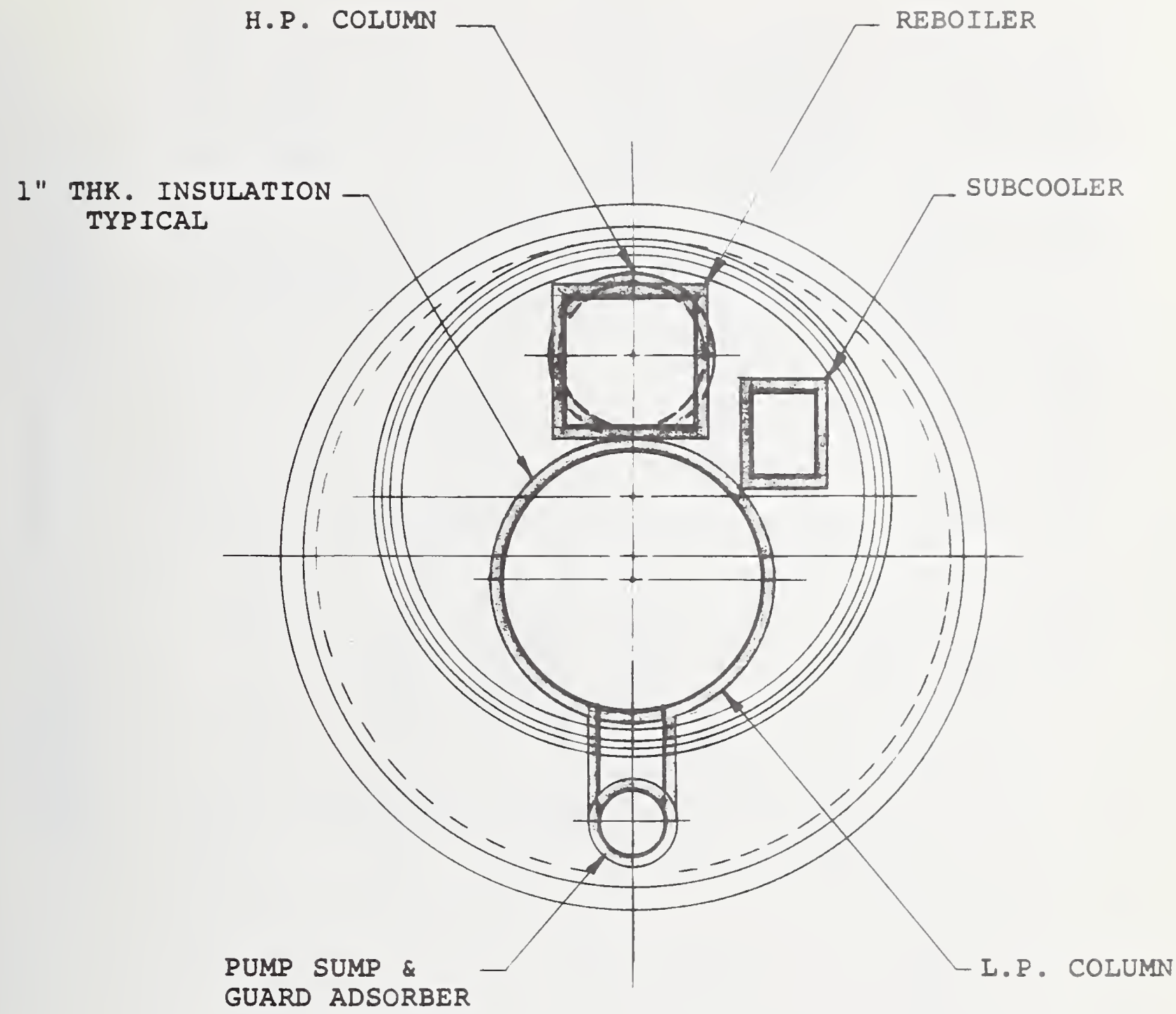

FIGURE 17. COLUMN COLD BOX PLAN VIEW 


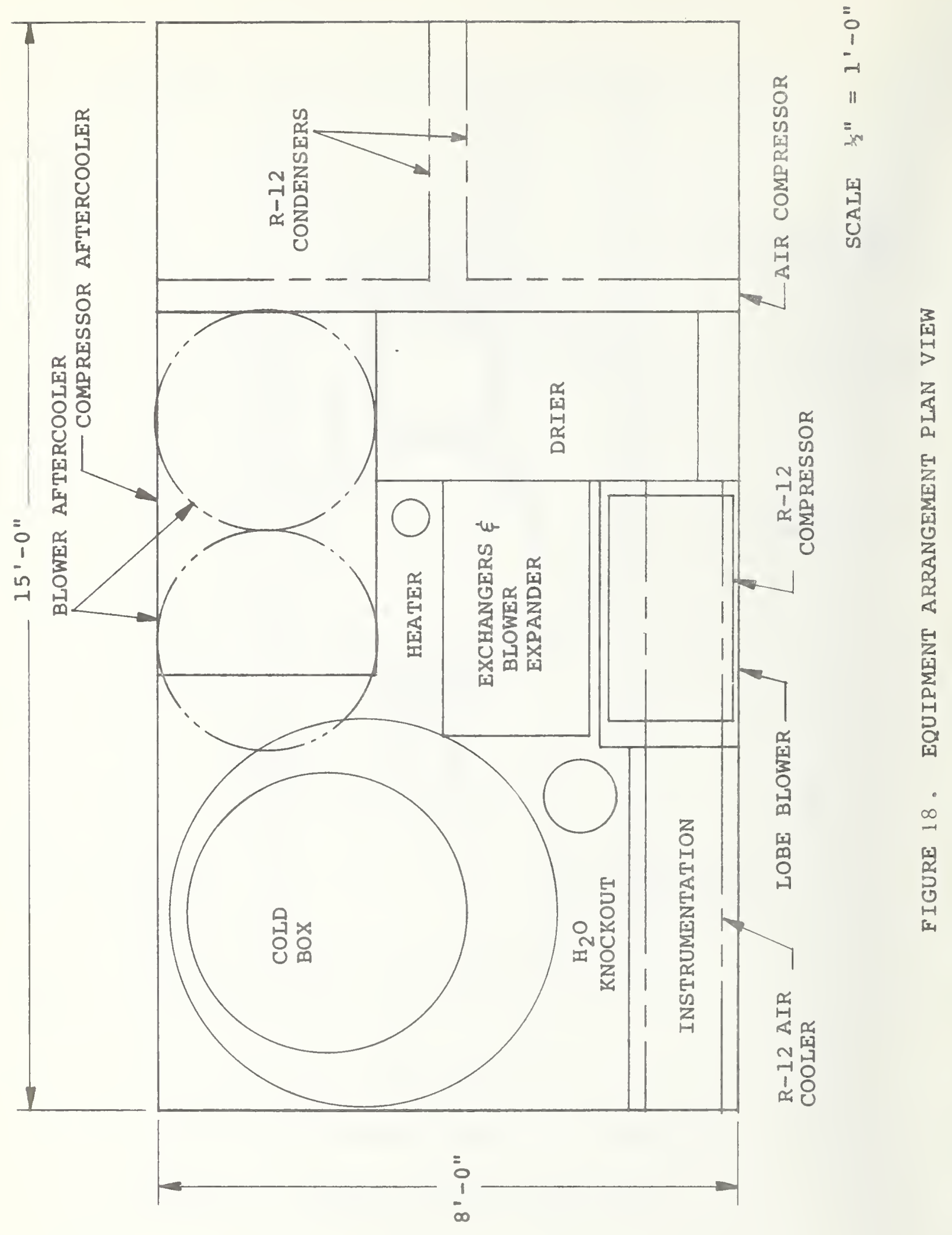




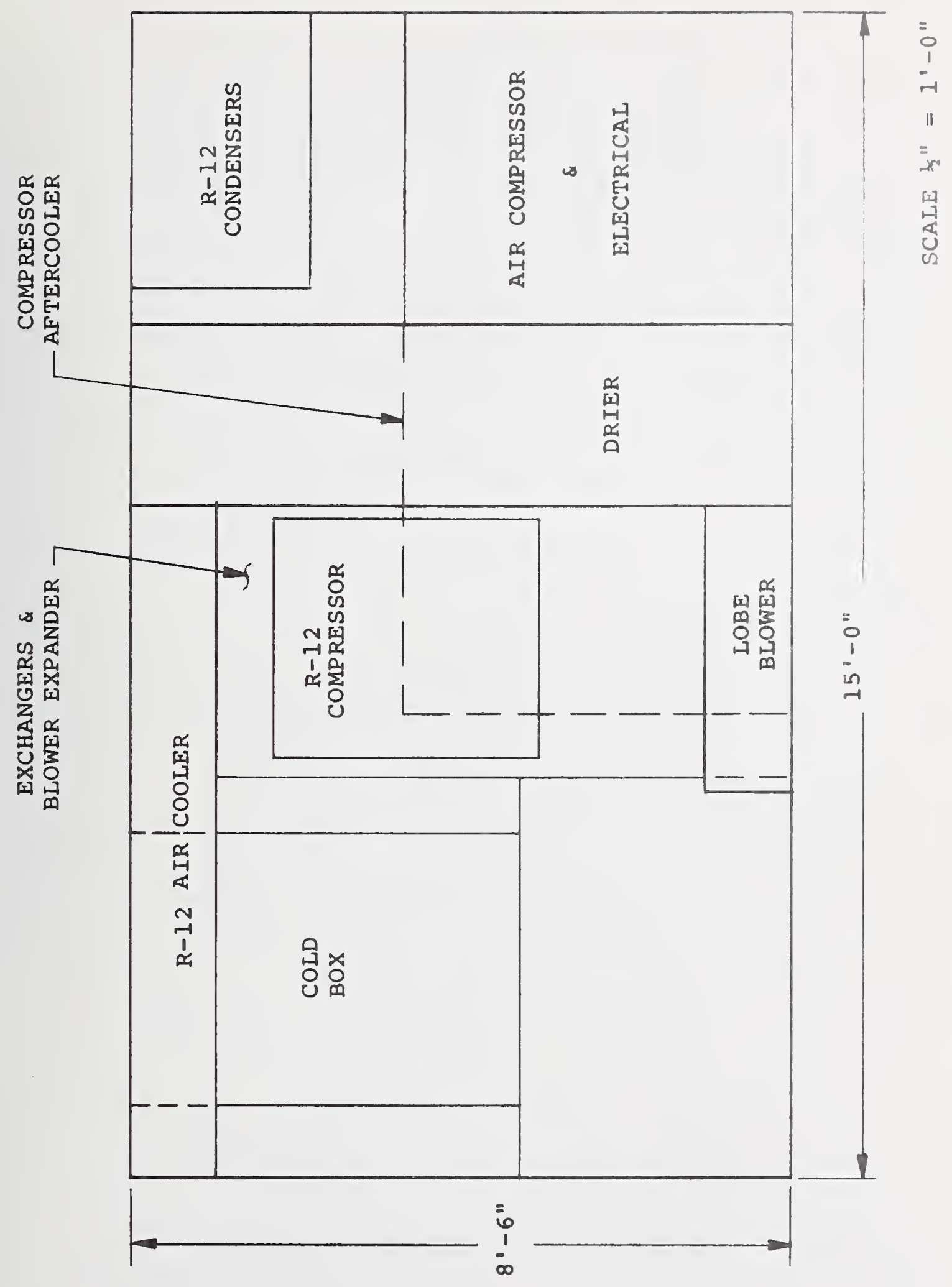

 


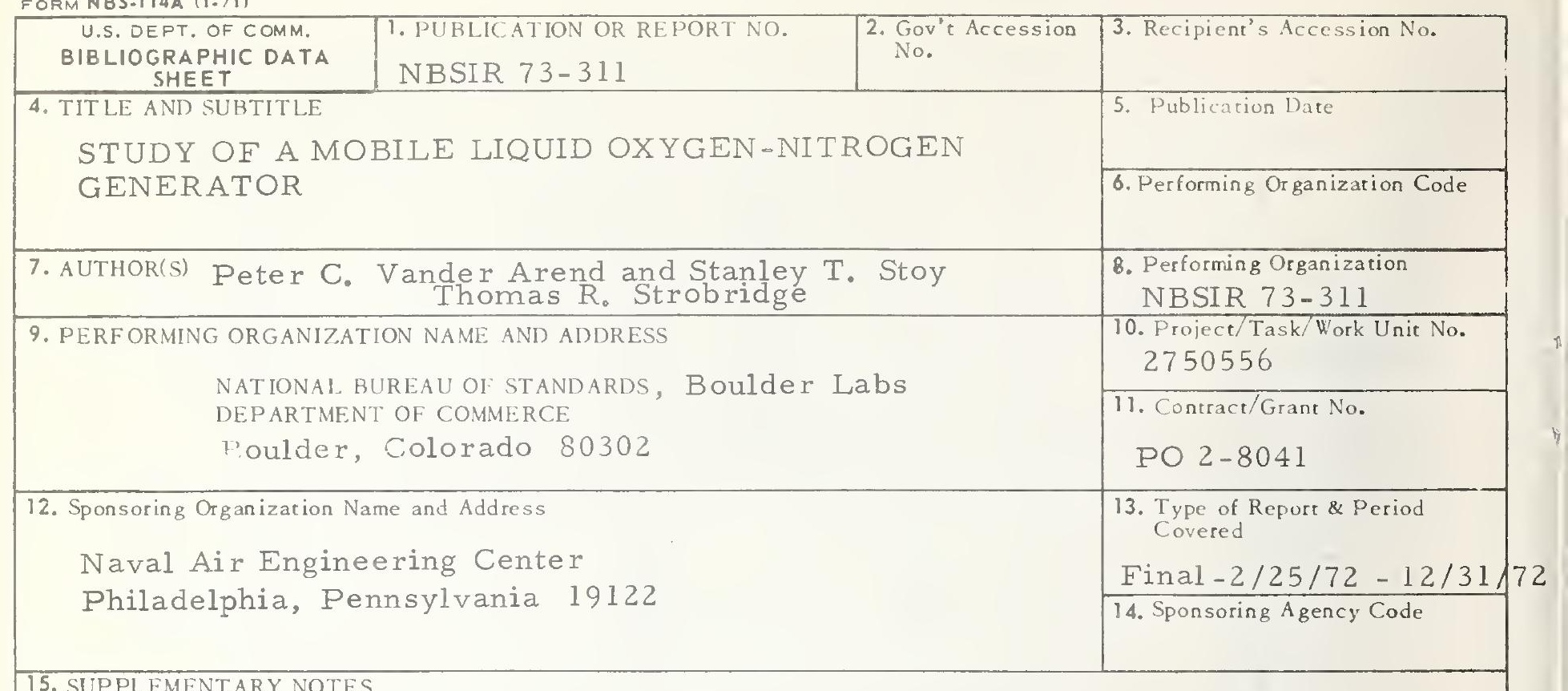

16. ABSTRACT (A 200-word or less factual summary of most significant information. If document includes a significant bibliography or literature survey, mention it here.)

It appears feasible to produce as much as 4 tons per day of liquid oxygen or liquid nitrogen of 99.5 percent purity with the equipment contained in an envelope $8 \mathrm{ft}$ by $8.5 \mathrm{ft}$ by $15 \mathrm{ft}$. The process cycle is completely described. Physical layouts were studied to as sure that the equipment required for the modified process would fit into the allotted space. A conceptual layout of the cold components, with the required vacuum insulation, was developed.

Major modifications to the existing 2 ton per day generator consisted of: a) the use of a blower on the expansion engine to pressurize part of the air stream to 105 psia, b) the use of a liquid oxygen pump to move liquid from the sump of the low pressure column to the reboiler side of the reboiler condenser and c) the purification of feed air in a separate system before it joins the major recycle stream. It was assumed that a compressor would supply air to the process at the same pressure and flow rate as the existing unit.

17. KEY WORDS (Alphabetical order, separated by semicolons)

Air separation; liquid nitrogen; liquid oxygen; mobile; purification.

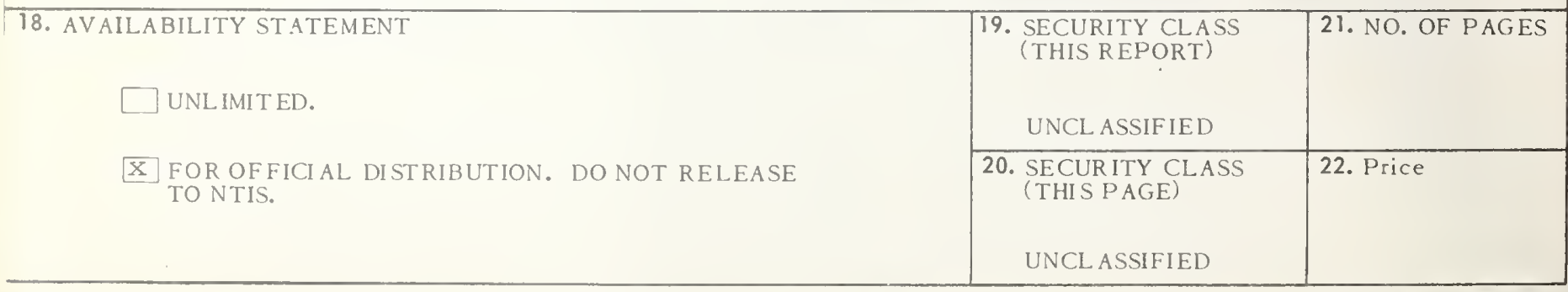



